\title{
UMA METODOLOGIA DE ESTIMAÇÃO DA CARGA TRIBUTÁRIA BRUTA BRASILEIRA EM BASES TRIMESTRAIS*
}

\author{
Cláudio H. dos Santos \\ Fernanda Reginatto Costa
}

\section{RESUMO}

Este artigo apresenta uma metodologia de estimação da carga tributária bruta brasileira (e de alguns de seus principais componentes) em níveis trimestrais, detalha os problemas práticos enfrentados na implementação dessa última (por volta de abril de 2008) e, por fim, apresenta as estimativas obtidas para o período que vai do primeiro trimestre de 1995 até o quarto trimestre de 2007.

Palavras-chave: carga tributária bruta brasileira, contas nacionais trimestrais brasileiras.

\begin{abstract}
This article presents a methodology for estimating quarterly figures for the Brazilian aggregate gross tax burden (and for some of its main components), details the practical problems one has to tackle when trying to implement it (as of April, 2008) and, finally, presents the estimates one obtains for the period beginning in the first quarter of 1995 and finishing in the fourth quarter of 2007.
\end{abstract}

Keywords: Brazilian quarterly national accounts, Brazilian gross tax burden.

JEL classification: C82, E62, O54.

* Os autores gostariam de agradecer os comentários de Sérgio Gobetti e de dois pareceristas anônimos sobre versões preliminares desse texto. Quaisquer erros remanescentes são de responsabilidade dos autores.

$\S$ Coordenador de Finanças Públicas da Diretoria de Estudos Macroeconômicos do IPEA. Endereço para contato: IPEA - Coordenação de Finanças Públicas - Setor Bancário Sul, Quadra 1, Bloco J, Ed. BNDES, S.721. Brasília - DF 70076 900. E-mail: claudio.santos@ipea.gov.br.

a Estudante de Economia da UNB e estagiária da Coordenação de Finanças Públicas do IPEA em 2007. Endereço para contato: SHIN, QI 1, Conjunto 6, Casa 21. Lago Norte Brasília-D71505-060. E-mail: fefita86@gmail.com.

Recebido em janeiro de 2007. Aceito para publicação em maio de 2008. 


\section{INTRODUÇÃO}

Ainda que haja alguma controvérsia sobre o tamanho preciso da carga tributária bruta brasileira (doravante apenas CTBB), ${ }^{1}$ não há dúvida que esta aumentou consideravelmente nos últimos 12 anos. Com efeito, (i) números do IBGE (2004a, 2007a e 2007b) apontam que a CTBB saltou de cerca de 26\% para 33,8\% do PIB entre 1995 e 2005; (ii) estimativas da Secretaria da Receita Federal do Brasil (SRFB, 2007) apontam que, em 2006, a CTBB atingiu $34,2 \%$ do PIB, ${ }^{3}$ e (iii) nossas próprias estimativas apontam que esse número foi de $34,5 \% \mathrm{em}$ 2006 e atingiu 35,7\% do PIB em 2007 (ver abaixo). Dados os óbvios impactos macroeconômicos/ redistributivos associados a uma elevação dessa natureza - cuja magnitude só encontra paralelo histórico (no pós-guerra) no período imediatamente posterior ao golpe de 1964 -, não é surpreendente que a CTBB esteja no centro do debate macroeconômico brasileiro atual. Com efeito, não são poucos os economistas que, como Velloso (2006, p. 1), acreditam que:

O Brasil não consegue crescer a taxas elevadas porque não resolveu o desequilíbrio crônico de suas contas públicas. (...). [É fato que], desde 1999 o Governo Federal tem gerado seguidos e crescentes superávits primários. Mas (...) [essa] geração de superávits primários tem sido baseada em aumentos de receita e corte do investimento público, e não em corte de gastos correntes, que continuam a crescer em ritmo elevado. Essa estratégia tem dois problemas. Em primeiro lugar, deprime o crescimento econômico de longo prazo. $O$ aumento da carga tributária onera os investimentos [privados], enquanto a redução dos investimentos públicos leva à deterioração da infra-estrutura necessária ao crescimento (transportes e energia, principalmente). Em segundo lugar, a estratégia tem vida curta, tanto porque não se pode aumentar indefinidamente a carga tributária (até tributar $100 \%$ da renda nacional), quanto porque não se pode reprimir o investimento público para o resto da vida: as estradas se transformam em crateras, a falta de energia elétrica leva a sucessivos apagões.

Por outro lado, também não são poucos os analistas que, ao analisarem as significativas melhorias observadas nas últimas duas décadas, tanto na extensão quanto na qualidade da oferta de bens públicos disponíveis aos cidadãos brasileiros, acabam por concluir, tal como Coutinho (2006, p. 9-10), que:

1 Grosso modo, a "carga tributária bruta" é o total de impostos, taxas e contribuições compulsoriamente pagos pelo setor privado ao governo (mesmo aquelas destinadas a financiar a poupança do próprio setor privado, como as contribuições previdenciárias e para o FGTS). O adjetivo "bruta" é adicionado para enfatizar que (ao contrário da carga tributária "líquida”) esse número não leva em conta o dinheiro que o governo "devolve” ao setor privado na forma de "transferências" como o pagamento de aposentadorias, pensões, seguros-desemprego, bolsas-família e etc. De acordo com o IBGE (2007a), as cargas tributárias "bruta” e "líquida” atingiram, respectivamente, 33,8\% e 19,3\% do PIB em 2005, de modo que as transferências do setor público para o privado atingiram $14,5 \%$ do PIB nesse mesmo ano.

2 Esses números são baseados nas “novas” contas nacionais “referência 2000" publicadas pelo IBGE em 21 de março de 2007 (IBGE, 2007b). Até essa data, acreditava-se que o salto recente da CTBB tinha sido ainda maior, saindo de cerca de 28\% do PIB em 1995 para perto de 38\% do PIB em 2006. Felizmente, a nova metodologia de cálculo do IBGE mostrou que a série "antiga" (ou "referência 1985") do PIB encontrava-se fortemente subestimada, de modo que os dados que utilizam o PIB "novo" são bem menores do que os que os que utilizam o PIB "antigo".

3 Os números da SRFB são calculados a partir de uma metodologia algo diferente da utilizada pelo IBGE. Ademais, aspectos da metodologia da SRFB parecem variar significativamente de ano para ano. 


\begin{abstract}
A pressão incisiva de diversos setores organizados da sociedade brasileira na defesa da extensão de direitos à massa da população, a compreensão de parte majoritária do Congresso Nacional da importância de assegurar prioridade orçamentária a certas áreas da política social e a disposição governamental em executar determinados programas de ação, fez que os indicadores sociais tivessem o comportamento observado nos últimos anos, expressando melhorias concretas em importantes dimensões da vida social.
\end{abstract}

Ambas as visões acima nos parecem defensáveis e evidenciam a enorme importância prática de se medir corretamente e acompanhar a evolução da CTBB ao longo do tempo. Por um lado, e a despeito da considerável evidência anedótica de que os níveis de eficiência do Estado brasileiro são baixos, é improvável que os aumentos de produtividade possíveis tenham o poder de tornar o gasto brasileiro per capita em bens públicos compatível com as justas demandas populares (e.g. por serviços públicos de saúde, educação, saneamento, transportes, segurança, controle de desmatamentos, estabilidade macroeconômica, etc.) apresentadas diariamente nos meios de comunicação. ${ }^{4}$ Mais dinheiro de impostos é necessário, portanto, para financiar incrementos em tais gastos sem que o crescimento da dívida pública se torne explosivo. ${ }^{5}$ Por outro lado, a literatura teórica sobre os determinantes do investimento privado agregado (e.g. vários dos modelos resenhados em ROMER, 2006, cap. 8) sugere(m), de fato, uma correlação negativa entre essa última variável e a carga de impostos sobre os lucros - e, portanto (e ceteris paribus), uma correlação negativa entre a taxa de crescimento de alguns componentes da carga tributária bruta e a taxa de crescimento do produto potencial de uma determinada economia. Percebe-se, assim, que o atual debate brasileiro guarda semelhanças com o gerado pela famosa "teoria do bolo” atribuída (justa ou injustamente) ao ex-ministro Delfim Netto nos anos de $1970{ }^{6}$

4 Infelizmente, são poucos estudos que se preocuparam em mensurar objetivamente o grau de eficiência/ineficiência (mesmo de setores) do setor público brasileiro. Dentre as exceções que confirmam a regra, destacamos os estudos de Afonso, Schuknecht e Tanzi (2006) e Ribeiro (2007), utilizando a metodologia DEA (do inglês "Data Envelopment Analysis"). Apesar do caráter preliminar desses estudos - e das inevitáveis imperfeições do referido método - os resultados já obtidos parecem indicar que há, de fato, espaço considerável para aumentos na eficiência do Estado brasileiro.

5 O que, aliás, ajuda a explicar o aumento da carga tributária ocorrido no Brasil na última década - de notável amadurecimento das instituições democráticas em uma sociedade (ainda) altamente desigual. Tal resultado é perfeitamente compatível, ainda, com modelos teóricos baseados nas preferências do "eleitor mediano". Ver Persson e Tabellini (2002, parte I) para uma resenha.

6 Naturalmente, partimos do pressuposto de que a "troca de alguns pontos de porcentagem na taxa de crescimento por reduções proporcionais nos índices de concentração [de renda]" é uma opção política perfeitamente legítima em uma sociedade democrática (principalmente se a mesma for altamente desigual), estando longe de ser "um verdadeiro conto do vigário" proposto por pessoas que querem "dividir a miséria de maneira mais eqüitativa” (DELFIM NETTO, 1973). Com efeito, e a despeito da força dos julgamentos de valor que freqüentemente são encontrados na literatura, não existe tal coisa como o "tamanho ótimo" da carga tributária de uma sociedade heterogênea e democrática. O problema, naturalmente, tem a ver com o famoso "Teorema da Impossibilidade de Arrow”, ou seja, com a impossibilidade de se agregar preferências de indivíduos diferentes em uma "função de bem-estar social” com propriedades minimamente desejáveis (ARROW, 1950, 1951). Ainda que esse último teorema não impeça os economistas de escolherem as "funções de bem-estar social" com que desejam trabalhar - e de fazerem recomendações de política baseadas (mesmo que apenas implicitamente) nessas últimas - parece-nos que a principal mensagem do mesmo é que cabe aos economistas também o papel de explicitar para a sociedade os trade-offs à disposição da mesma, a fim de estimular o debate democrático sobre esses últimos. 
Este artigo visa contribuir para melhor quantificação e compreensão do aparente tradeoff entre tributação/redistribuição e crescimento atualmente à disposição dos brasileiros ${ }^{7}-\mathrm{e}$, em particular, para o estudo do tema a partir de métodos macroeconométricos - apresentando (uma metodologia de construção de) estimativas trimestrais da CTBB para o período entre o primeiro trimestre de 1995 e o quarto trimestre de $2007 .^{8}$ Tais estimativas seguem tão fielmente quanto possível as definições utilizadas na construção dos dados anuais do IBGE (e, portanto, a metodologia das contas nacionais) e foram construídas a partir: (i) dos referidos dados anuais, e (ii) da compilação de dados mensais e/ou trimestrais de várias fontes, dentre as quais a Caixa Econômica Federal (que disponibiliza dados trimestrais sobre a arrecadação bruta do FGTS), o próprio IBGE (que disponibiliza dados sobre os "impostos sobre produtos líquidos de subsídios" nas contas nacionais trimestrais), e, crucialmente, a Secretaria do Tesouro Nacional (que disponibiliza dados desagregados mensais sobre a arrecadação de tributos, taxas e contribuições da União). Foram utilizadas, ainda, algumas hipóteses simplificadoras (ainda que plausíveis) sobre a arrecadação de tributos - geralmente estaduais e municipais - para os quais não encontramos dados de alta freqüência.

A despeito do calor do debate sobre as causas e conseqüências do atual processo de elevação da CTBB, é importante notar que a teoria econômica tem bastante mais a dizer sobre a composição dessa última variável que sobre o tamanho da mesma. ${ }^{10}$ Acreditamos, pois, que uma segunda contribuição deste artigo é a apresentação de séries trimestrais também para os principais componentes da CTBB, notadamente para as "contribuições previdenciárias totais" (incluindo contribuições para o FGTS e para o PIS-PASEP), para os "impostos sobre a renda, a propriedade e o capital” e para os chamados “outros impostos ligados à produção” (e.g. saláriofamília, contribuições para o sistema "S" e taxas diversas).

Tendo em vista esses objetivos, optamos por dividir o restante deste artigo em seis seções. Inicialmente, na seção 2, apresentamos os dados a serem estimados e nossa estratégia geral de estimação. Em seguida, nas seções 3, 4 e 5, discutimos como obter estimativas trimestrais dos três componentes "desconhecidos" da CTBB trimestral, quais sejam, as "contribuições previdenciárias”, os "impostos sobre a renda, a propriedade e o capital” e os "outros impostos ligados à produção", respectivamente. Uma vez de posse de nossas estimativas "finais" da carga tributária bruta em níveis trimestrais (reproduzidas no Apêndice 1), discutimos então, na seção 6, a precisão e a robustez das mesmas. Finalmente, na sétima e última seção do texto, apresentamos breves notas à guisa de conclusão.

7 Ver Marglin e Bhaduri (1990) e Persson e Tabellini (2000, cap.14) para uma discussão das bases teóricas - respectivamente "heterodoxas" e "ortodoxas" - desse trade-off.

8 O grande número de quebras estruturais ocorridas na economia brasileira nas ultimas três décadas faz com que haja poucos motivos para acreditar nos resultados de estudos econométricos realizados com dados anuais.

9 Notamos que todos os dados utilizados neste artigo estão disponíveis gratuitamente na Internet.

10 Tanzi e Zee (2000) têm opinião semelhante. 


\section{CONCEITOS BÁSICOS E A ESTRATÉGIA DE ESTIMAÇÃO UTILIZADA NESTE TRA- BALHO}

Começamos notando que as contas nacionais brasileiras - ou, mais precisamente, a tabela sinótica 20 do Sistema de Contas Nacionais Brasil 2004-2005 (IBGE, 2007a doravante SCN 2005) - dividem a arrecadação total de impostos e contribuições em cinco categorias, quais sejam: (i) arrecadação com "impostos sobre produtos" (IPs); (ii) arrecadação com "outros impostos ligados à produção" (OILPs); (iii) arrecadação com impostos sobre a renda e a propriedade (IRPs); (iv) arrecadação com contribuições previdenciárias (CPs, incluindo os gastos governamentais com o financiamento da seguridade social dos funcionários públicos e a arrecadação bruta do FGTS e do PIS-PASEP), e, finalmente, (v) arrecadação com "impostos sobre o capital". A chamada "carga tributária bruta", tal como definida na tabela sinótica 19 do SCN 2005, é simplesmente a soma dos itens (i) a (v) dividida pelo PIB em um dado período contábil (ver Tabela 1).

Infelizmente, somente a arrecadação com os "impostos sobre produtos" é disponibilizada em bases trimestrais pelo IBGE (nas contas nacionais trimestrais) - e mesmo assim apenas "líquida de subsídios aos produtos" ${ }^{11}$ de modo que tivemos que estimar os demais componentes da CTBB trimestral. A estratégia geral seguida em todos os casos foi a mesma e pode ser resumida em três passos. Inicialmente, tentou-se reconstruir, com base nas notas metodológicas das contas nacionais (IBGE, 2004b e 2007c) e em dados mensais ou trimestrais de diversas fontes, os valores anuais reportados no SCN 2003 (IBGE, 2004a) para o período 1995-1999 e no SCN 2005 (IBGE, 2007a) para o período 2000-2005. Tendo os valores reconstruídos se revelado próximos ou superiores a $90 \%$ dos totais anuais em praticamente todos os casos relevantes, supôs-se (quando na falta de hipótese melhor) que as parcelas não explicadas desses últimos se distribuíram uniformemente ao longo do ano. Finalmente, os valores reportados para os anos de $2006 \mathrm{e}$ 2007 foram calculados supondo-se que a razão entre os valores reconstruídos e os valores totais nesses anos foi igual à observada em 2005.

11 Felizmente, para nossos propósitos, os subsídios aos produtos foram nulos entre 1995 e 1999 e se mostraram muito pequenos em relação aos impostos sobre produtos entre 2000 e 2005 (tendo variado entre 0,14\% e 2,54\% desses últimos). Ainda assim, optamos por construir nossa série de "impostos sobre produtos” assumindo que: (i) a sazonalidade trimestral da mesma foi idêntica à da série dos “impostos sobre produtos líquidos de subsídios” entre 2000 e 2005 (período para o qual existem dados anuais para os subsídios sobre produtos), e (ii) que o peso dos subsídios nos impostos sobre produtos em 2006 e 2007 foi igual ao observado em 2005 (i.e. 0,5\%). 
Tabela 1 - Componentes da CTBB em 2005 (em R\$ bilhões )

\begin{tabular}{lrrrr}
\hline & \multicolumn{1}{c}{ Total $^{12}$} & Federal & Estadual & Municipal \\
\hline Total & 726,35 & 489,26 & 195,11 & 41,98 \\
Impostos sobre Produtos & 306,54 & 138,99 & 154,11 & 13,45 \\
Outros Impostos Ligados à Produção & 27,98 & 14,40 & 7,32 & 6,26 \\
Impostos sobre a Renda e a Propriedade & 202,47 & 167,51 & 18,97 & 16,00 \\
Contribuições Previdenciárias (INSS + FGTS + & 186,11 & 168,32 & 13,83 & 3,97 \\
Funcionalismo Público) & 3,25 & 0,05 & 0,89 & 2,31 \\
Impostos sobre o Capital & & & & \\
\hline
\end{tabular}

Fonte: IBGE (2007a, tabela sinótica 20).

Ainda que a estratégia descrita acima seja conceitualmente muito simples, a implementação da mesma (em abril de 2008) envolveu um número relativamente grande de decisões não triviais acerca de como lidar, dentre outras coisas, com observações aberrantes, séries incompletas e diferenças definicionais entre as bases de dados relevantes. As seções seguintes detalham os procedimentos adotados.

Antes de prosseguirmos, porém, cumpre notar que não desconhecemos - e, na verdade, aplaudimos - os esforços de vários economistas brasileiros (e.g. AFONSO, ARAÚJO; KHAIR, 2005; AFONSO; MEIRELLES, 2006) no sentido de propor metodologias de cálculo da CTBB anual alternativas à utilizada pelo IBGE. Optamos, entretanto, pela metodologia das contas nacionais por acreditarmos que a mesma - além de facilitar comparações internacionais - deve ser utilizada como um benchmark para a apreciação dos méritos relativos de metodologias alternativas. ${ }^{13}$ Ademais, acreditamos que mesmo o crítico mais ferrenho das contas nacionais irá concordar que a metodologia proposta neste trabalho pode ser facilmente adaptada para possibilitar o cálculo trimestral de outros conceitos de CTBB.

12 Como o PIB de 2005 calculado pelo IBGE foi de R $\$ 2147,24$ bilhões, a carga tributária bruta medida como porcentagem do PIB nesse ano foi de 33,8\% (resultado publicado na tabela sinótica 19 do SCN 2005).

13 Como se sabe, a metodologia das contas nacionais foi agraciada com o prêmio Nobel de 1984 e está embasada em várias décadas de pesquisa contínua no âmbito de organizações multilaterais. Ver, a esse respeito, Stone (1986) e Organização das Nações Unidas (1993). 


\section{ESTIMANDO AS CONTRIBUIÇÕES PREVIDENCIÁRIAS TRIMESTRAIS (INCLUINDO A ARRECADAÇÃO BRUTA DO FGTS E DO PIS-PASEP)}

Até onde sabemos, não existem dados de alta freqüência sobre a arrecadação agregada de Estados e municípios com contribuições previdenciárias. ${ }^{14}$ Assim sendo, foi animador para os nossos propósitos notar que a parcela das contribuições estaduais e municipais nas contribuições previdenciárias totais (i.e a soma das contribuições aos institutos oficiais de previdência, incluindo FGTS e PIS-PASEP, e das contribuições do funcionalismo público) se mostrou pequena - ainda que relativamente crescente - no período 1995-2006 (ver Tabela 2).

\section{Tabela 2 - Arrecadação das contribuições previdenciárias por entes da Federação (em R\$ bilhões correntes)}

\begin{tabular}{rccc}
\hline Ano & Total & Federal & Estadual e Municipal \\
\hline 1995 & 47,43 & $44,26(93,31 \%)$ & $3,17(6,69 \%)$ \\
1996 & 66,00 & $62,22(94,26 \%)$ & $3,79(5,74 \%)$ \\
1997 & 71,84 & $67,91(94,53 \%)$ & $3,93(5,47 \%)$ \\
1998 & 77,81 & $73,20(94,08 \%)$ & $4,61(5,92 \%)$ \\
1999 & 85,37 & $79,66(93,31 \%)$ & $5,71(6,69 \%)$ \\
2000 & 94,84 & $87,40(92,16 \%)$ & $7,43(7,86 \%)$ \\
2001 & 107,78 & $98,88(91,75 \%)$ & $8,90(8,25 \%)$ \\
2002 & 122,63 & $111,67(91,06 \%)$ & $10,96(8,94 \%)$ \\
2003 & 141,33 & $128,25(90,74 \%)$ & $13,08(9,26 \%)$ \\
2004 & 167,68 & $151,29(90,22 \%)$ & $16,39(9,78 \%)$ \\
2005 & 186,11 & $168,32(90,44 \%)$ & $17,79(9,56 \%)$ \\
2006 & 215,75 & $195,62(90,66 \%)$ & $20,13(9,34 \%)$ \\
\hline
\end{tabular}

Fonte: Elaboração dos autores com base em IBGE (2004a e 2007b) e SRFB (2007).

Nota: Dados anteriores a 2000 são do SCN 2003 (IBGE, 2004a), ajustados para se tornarem compatíveis com os dados do SCN, 2005..$^{15}$ Dados de 2000 até 2005 são do SCN, 2005. Dados de 2006 são estimativas a partir dos dados da Secretaria da Receita Federal do Brasil (SRFB, 2007).

Nosso segundo passo foi tentar reconstruir os dados anuais da arrecadação total das contribuições previdenciárias federais tais como definidas no SCN 2005, usando dados de alta freqüência de outras fontes (ver Apêndice 1 para detalhes). Para nossa satisfação, conseguimos 100\% de precisão em vários anos (ver Tabelas 3 e 4). Antes de apresentarmos o grau de precisão final

14 Nesse contexto, cumpre louvar o fato de a Secretaria do Tesouro Nacional ter recentemente disponibilizado na Internet os "Indicadores Fiscais e de Endividamento" dos Estados e municípios brasileiros (STN, 2007c) com dados mensais sobre as contribuições previdenciárias de Estados e municípios desde 2001. A despeito desses dados (ainda) apresentarem problemas importantes - em particular, a necessidade de manipular individualmente os arquivos com as séries de cada Estado/município e o fato de observações em séries importantes parecerem inconsistentes entre si -, a mera divulgação dos mesmos já traz a promessa de dias melhores para a literatura econométrica sobre os impactos "reais" da arrecadação tributária no Brasil.

15 As contribuições previdenciárias reportadas pelo SCN 2003 (IBGE, 2004a) não incluem as contribuições para o PIS-PASEP, de modo que tivemos que adicionar essas últimas aos valores reportados no SCN 2003 a fim de tornálos comparáveis com os valores reportados no SCN 2005. 
de nossas estimativas das contribuições previdenciárias totais, entretanto, cumpre destacar que é útil dividi-las (tal como ocorre no SCN 2005) em "contribuições previdenciárias do funcionalismo público" (doravante CPFPs) e "contribuições aos institutos oficiais de previdência” (doravante CIOPs, que incluem as contribuições para o INSS, FGTS e PIS-PASEP). Com efeito, as Tabelas 3 e 4 a seguir deixam claro que o grau de precisão alcançado na primeira categoria é bem menor do que na segunda (dado o maior peso de Estados e municípios nas contribuições para a previdência dos servidores públicos). ${ }^{16,17}$ Infelizmente, mudanças ocorridas nas séries de alta freqüência utilizadas em nossas estimativas ${ }^{18}$ fizeram com que, a partir de 2005, não pudéssemos mais desagregar essas últimas em CIOPs e CPFPs. Assim, as Tabelas 3 e 4 vão apenas até 2004 e nossas estimativas agregadas para 2005, 2006 e 2007 são apresentadas na Tabela 5. Felizmente, o grau de precisão das estimativas agregadas foi superior a $85 \%$ em todos os anos cobertos em nossa amostra (ver Tabelas 4 e 5).

\section{Tabela 3 - Graus de precisão das estimativas finais das "Contribuições aos Institutos Oficiais de Previdência" (dados em R \$ bilhões correntes e em \%)}

\begin{tabular}{lcccccccc}
\hline Ano & $\begin{array}{c}\text { ClOPs } \\
\text { estimadas } \\
\text { (excluindo 0 } \\
\text { PIS-PASEP) }\end{array}$ & $\begin{array}{c}\text { SCN 2003 } \\
\text { (ClOPs } \\
\text { federais, } \\
\text { excluem 0 } \\
\text { PIS-PASEP) }\end{array}$ & Precisão & $\begin{array}{c}\text { ClOPs } \\
\text { estimadas } \\
\text { (incluindo 0 } \\
\text { PIS-PASEP) }\end{array}$ & $\begin{array}{c}\text { SCN 2005 } \\
\text { (CIOPs } \\
\text { federais, } \\
\text { Incluem 0 } \\
\text { PIS-PASEP) }\end{array}$ & Precisão & $\begin{array}{c}\text { SCN 2005 } \\
\text { (CIOPs } \\
\text { totais) }\end{array}$ & Precisão \\
\hline 1995 & 35,38 & 35,38 & $100,00 \%$ & 41,26 & $41,26 \mathrm{PH}$ & $100,00 \%$ & $44,04 \mathrm{PH}$ & $93,69 \%$ \\
1996 & 52,28 & 52,38 & $99,83 \%$ & 59,41 & $59,51 \mathrm{PH}$ & $99,85 \%$ & $62,68 \mathrm{PH}$ & $94,78 \%$ \\
1997 & 56,89 & 57,94 & $98,19 \%$ & 64,14 & $65,19 \mathrm{PH}$ & $98,39 \%$ & $68,14 \mathrm{PH}$ & $94,13 \%$ \\
1998 & 61,84 & 63,50 & $97,39 \%$ & 68,91 & $70,57 \mathrm{PH}$ & $97,65 \%$ & $74,18 \mathrm{PH}$ & $92,90 \%$ \\
1999 & 66,93 & 66,93 & $100,00 \%$ & 76,38 & $76,38 \mathrm{PH}$ & $100,00 \%$ & $80,84 \mathrm{PH}$ & $94,48 \%$ \\
2000 & 74,19 & 74,19 & $100,00 \%$ & 83,67 & 83,70 & $99,97 \%$ & 83,79 & $99,86 \%$ \\
2001 & 83,11 & 83,50 & $99,54 \%$ & 94,30 & 94,71 & $99,56 \%$ & 94,83 & $99,44 \%$ \\
2002 & 91,26 & 92,09 & $99,10 \%$ & 103,73 & 106,23 & $97,69 \%$ & 107,08 & $96,87 \%$ \\
2003 & 103,89 & 103,89 & $100,00 \%$ & 120,39 & 122,78 & $98,05 \%$ & 124,20 & $96,93 \%$ \\
2004 & 120,98 & ND & ND & 140,26 & 142,93 & $98,13 \%$ & 145,12 & $96,65 \%$ \\
\hline
\end{tabular}

Fonte: Elaboração dos autores com base em IBGE (2004a e 2007a) e vários números dos relatórios de adm. da CEF.

Nota: ND e PH indicam, respectivamente, dados “indisponíveis” e "formalmente indisponíveis mas obtidos por hipótese".

16 Note-se que (a partir de 1996) nossas estimativas das CPFPs federais (reportadas na Tabela 4) são idênticas às reportadas no SCN 2003 e apenas marginalmente diferentes dos valores reportados no SCN 2005.

17 Chama a atenção, ainda, o fato de os critérios do IBGE terem se mostrado algo erráticos (salvo explicações a serem publicadas em uma possível versão final da metodologia do SCN 2005 - a disponível atualmente é uma versão para "informação e comentários”) no que tange à classificação das contribuições previdenciárias de Estados e municípios entre "contribuições p/ o INSS" e "contribuições para a previdência dos servidores públicos”. Uma vez que os problemas advindos desse fato afetam principalmente a desagregação (e não o total) das contribuições previdenciárias estaduais e municipais, os mesmos não têm maiores implicações para nossas estimativas.

18 Mais precisamente, a partir de 2005, a variável "contr. (patronal) de servidor ativo civil" parece ter sido incorporada à variável "contr. previd dos órgãos do poder público" nos dados de STN (2007a) - ver Apêndice 1 para detalhes.

19 Notamos, uma vez mais, que o SCN 2003 não considera as contribuições para o PIS-PASEP como parte das CIOPs - daí termos que acrescentar o valor das contribuições ao PIS-PASEP às CIOPs reportadas no SCN 2003 a fim de torná-las comparáveis às CIOPs reportadas no SCN 2005.

20 Uma vez que os dados do SCN 2005 começam no ano 2000, os valores dos CIOPs federais SCN 2005 foram construídos somando-se os CIOPs federais do SCN 2003 com as contribuições para o PIS-PASEP reportadas nessa última publicação. 
Tabela 4 - Graus de precisão das estimativas finais das contribuições previdenciárias dos funcionários públicos (CPFPs) e das contribuições previdenciárias totais (CPs) até 2004 (dados em $\mathrm{R} \$$ bilhões correntes e em \%)

\begin{tabular}{cccccccc}
\hline Ano & $\begin{array}{c}\text { CPFPs } \\
\text { federais } \\
\text { estimadas } \\
(1)\end{array}$ & $\begin{array}{c}\text { CPFPs } \\
\text { totais(2) }\end{array}$ & Precisão & $\begin{array}{c}\text { CPs totais } \\
\text { estimadas = (1) + } \\
\text { ClOPsestimadas } \\
\text { (Tabela 3) }\end{array}$ & $\begin{array}{c}\text { CPs_totais (incluindo } \\
\text { o PIS/PASEP) }=(2) \\
\text { + ClOPs totais(ver } \\
\text { Tabela 3) }\end{array}$ & $\begin{array}{c}\text { CPs não } \\
\text { explicadas }\end{array}$ & Precisão \\
\hline 1995 & 2,227 & $3,38^{\dagger}$ & $65,89 \%$ & 43,48 & $47,43^{\dagger}$ & 3,95 & $91,69 \%$ \\
1996 & 2,711 & $3,33^{\dagger}$ & $81,41 \%$ & 62,15 & $66,00^{\dagger}$ & 3,85 & $94,17 \%$ \\
1997 & 2,723 & $3,70^{\dagger}$ & $73,59 \%$ & 66,85 & $71,84^{\dagger}$ & 4,99 & $93,07 \%$ \\
1998 & 2,629 & $3,62^{\dagger}$ & $72,64 \%$ & 71,54 & $77,80^{\dagger}$ & 6,26 & $91,95 \%$ \\
1999 & 3,277 & $4,53^{\dagger}$ & $72,34 \%$ & 79,67 & $85,37^{\dagger}$ & 5,70 & $93,31 \%$ \\
2000 & 3,517 & 11,05 & $31,83 \%$ & 87,20 & 94,84 & 7,64 & $91,93 \%$ \\
2001 & 4,126 & 12,95 & $31,86 \%$ & 98,45 & 107,78 & 9,33 & $91,34 \%$ \\
2002 & 5,366 & 15,55 & $34,51 \%$ & 109,09 & 122,63 & 13,54 & $88,96 \%$ \\
2003 & 5,283 & 17,13 & $30,84 \%$ & 125,68 & 141,33 & 15,65 & $88,92 \%$ \\
2004 & 7,924 & 22,56 & $35,13 \%$ & 148,20 & 167,68 & 19,48 & $88,38 \%$ \\
\hline
\end{tabular}

Fonte: Elaboração dos autores com base em IBGE (2004a e 2007a), STN (2007a e 2007b) e vários números dos relatórios de administração da CEF.

Nota: † indica um dado do SCN 2003 (ajustado, se necessário, p/ o SCN 2005). ${ }^{21}$

Tabela 5 - Graus de precisão das estimativas finais das CPs totais 2004-2007 (dados em R\$ bi-lhões correntes e em \%). O dado de 2006 foi obtido de SRFB(2007)

\begin{tabular}{lllcl}
\hline & CPs totais estimadas & CPs totais & CPs não explicadas & Precisão \\
\hline 2004 & 148,20 & 167,68 & 19,48 & $88,38 \%$ \\
2005 & 165,01 & 186,11 & 21,10 & $88,66 \%$ \\
2006 & 186,51 & 215,75 & 29,24 & $86,45 \%$ \\
2007 & 210,29 & $243,26 \mathrm{PH}$ & $32,97 \mathrm{PH}$ & $86,45 \% \mathrm{PH}$ \\
\hline
\end{tabular}

Fonte: Elaboração dos autores com base em IBGE (2007a), SRFB (2007), STN (2007a e 2007b) e vários números dos relatórios de administração da CEF.

Nota: O dado de 2007 foi obtido assumindo-se que o "grau de precisão total" das nossas estimativas em 2007 foi igual ao observado em 2006.

Dois pontos adicionais devem ser frisados antes de prosseguirmos. Inicialmente, repetimos que a parcela inexplicada das CPs consiste essencialmente das CPs de Estados e municípios (ainda que a precisão de nossas estimativas das CPs federais tenha caído um pouco após 2003). Uma vez que não temos, a princípio, nenhum motivo para supor que as CPs de Estados e mu-

21 Assume-se, ainda (e talvez heroicamente), que as significativas revisões nas CPs estaduais para a previdência pública reportadas no SCN 2005 (em relação ao SCN 2003) se deveram apenas a reclassificações de antigas contribuições estaduais e municipais ao INSS para contribuições estaduais e municipais à previdência dos servidores públicos. Tais reclassificações (que no SCN 2003 ocorreram a partir de 2002) explicam a grande queda (aumento) nos graus de precisão de nossas estimativas das CPFPs (CIOPs) a partir do ano 2000. 
nicípios tenham uma sazonalidade diferente das CPs federais - aumentando ligeiramente de valor no final do ano, com o pagamento do décimo terceiro salário - optamos por assumir que o comportamento sazonal da parcela inexplicada das CPs foi o mesmo exibido pela parcela explicada das mesmas. ${ }^{22}$ As estimativas obtidas com essa hipótese estão reproduzidas no Gráfico 1 a seguir e no Apêndice 2 ao final do texto.

Em segundo lugar, notamos que os dados oficiais do SCN 2003 (IBGE, 2004a) e da STN (2007a) para as CIOPs no ano de 1995 (i.e. R\$35,38 bilhões, excluindo as contribuições para o PIS-PASEP) parecem estar errados. Não apenas esse valor implica um salto (improvável) de mais de 1\% do PIB nas CPs totais entre 1995 e 1996, como o mesmo difere muito significativamente dos dados reportados pela Secretaria da Receita Federal do Brasil (e.g. SFRB, 1999) e pelo Ministério da Previdência Social (2007). ${ }^{23}$ Assim sendo, optamos por utilizar o dado da SRFB para o ano de 1995 (i.e por assumir que as CIOPs federais excluindo o PIS-PASEP foram de $\mathrm{R} \$ 41,95$ bilhões em 1995) em nossas estimativas finais (ver Apêndice 2).

\section{Gráfico 1 - Estimativas trimestrais das contribuições previdenciárias totais (em $\mathbf{R} \$$ bilhões)}

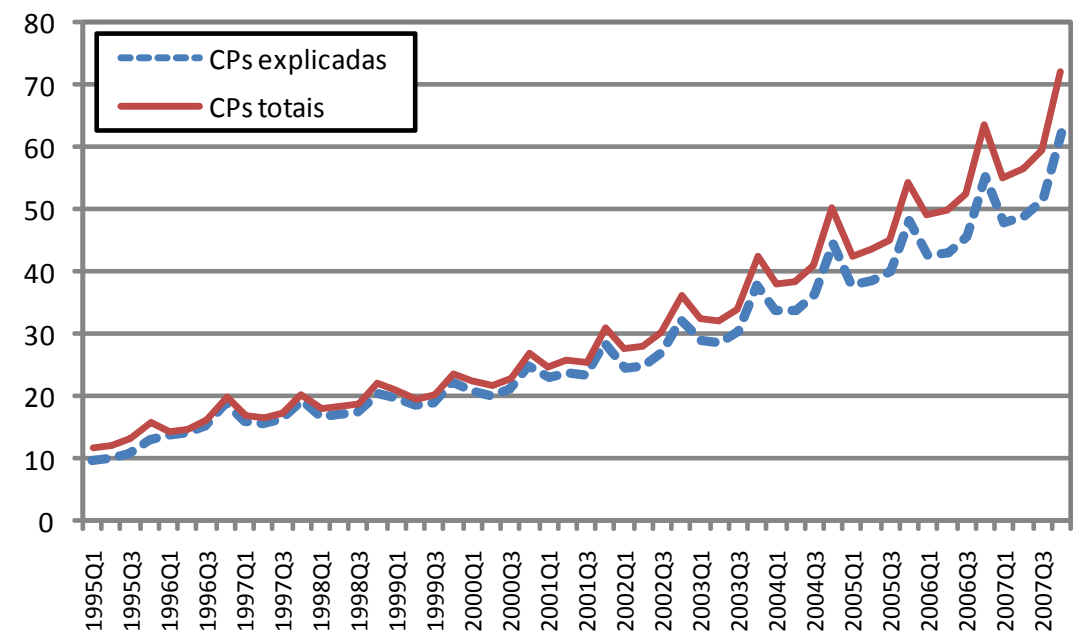

22 Cumpre notar, entretanto, que uma análise preliminar dos dados mensais dos "Indicadores de Fiscais e de Endividamento" da STN acerca das contribuições previdenciárias de São Paulo, Rio de Janeiro, Minas Gerais, Rio Grande do Sul, Paraná e Distrito Federal - utilizados como aproximações das CPs dos Estados (quantitativamente bem mais importantes que as dos municípios) - exibiram um padrão sazonal algo errático e não particularmente diferente da hipótese de distribuição uniforme ao longo do ano. Dados os (relativamente) pequenos montantes envolvidos, e o brando padrão sazonal da série "explicada”, nossas estimativas finais mudam muito pouco se supusermos que as CPs inexplicadas se comportam de acordo com essa última hipótese.

23 Ao contrário do que ocorre, por exemplo, nos anos de 1996 ou 1997. O fato de ambos os dados do SCN 2003 e da STN (2007a) apresentarem o mesmo problema indica que a origem do mesmo está em algum equívoco na contabilização dos dados de 1995 no sistema de administração financeira (SIAFI) do governo federal. 


\section{ESTIMANDO OS “IMPOSTOS SOBRE RENDA E PROPRIEDADE” E OS “IMPOSTOS SOBRE O CAPITAL” EM BASES TRIMESTRAIS}

Começamos notando que os cinco mais importantes impostos sobre a renda e propriedade (IRPs) listados no SCN 2005 - a saber, os impostos de renda (IR), sobre veículos automotores (IPVA) e sobre a propriedade predial e territorial urbana (IPTU), além das contribuições sobre movimentações financeiras (CPMF) e sobre o lucro líquido de pessoas jurídicas (CSSL) - responderam por cerca de $98 \%$ da arrecadação conjunta dos IRPs e dos (pouco relevantes) "impostos sobre o capital” no período 2000-2005.

Felizmente, a STN e o CONFAZ disponibilizam séries mensais para quatro desses cinco impostos mais importantes (ver Apêndice 1 para detalhes) - a única exceção é o IPTU, por se tratar de um imposto municipal. Além disso, o CONFAZ disponibiliza ainda uma série mensal para o "imposto [estadual] sobre transmissão causa mortis e doações" (ITCMD), um dos chamados "impostos sobre o capital”. A arrecadação agregada dessas cinco séries aparece na Tabela 6 a seguir como o "total explicado sem o IPTU" da arrecadação conjunta dos IRPs e ICs (doravante IRPCs) - parcela essa que ficou próxima de $86 \%$ do total em anos recentes.

Há que se fazer, entretanto, pelo menos cinco qualificações importantes a respeito dos resultados reportados na Tabela 6. Em primeiro lugar, notamos que o SCN 2005 (IBGE, 2007b) difere do SCN 2003 (IBGE, 2004a) pelo fato de incluir o imposto de renda retido na fonte dos servidores públicos estaduais e municipais no cálculo da arrecadação total do IR. ${ }^{24}$ Como o SCN 2005 não disponibiliza dados para o período 1995-1999, tivemos, então, que ajustar os dados do SCN 2003 sobre a arrecadação total dos IRPCs nesses anos a fim de torná-los compatíveis com os dados do SCN 2005. ${ }^{25}$ Em segundo lugar, notamos que ambas as séries mensais do IPVA e do ITCMD mencionadas anteriormente estão disponíveis apenas a partir de 1997, de modo que fomos obrigados a assumir que a sazonalidade trimestral da arrecadação desses impostos em 1995 e 1996 foi similar à apresentada em 1997. ${ }^{26}$ Em terceiro lugar, notamos que os dados dos Indicadores Fiscais e de Endividamento (STN, 2007c) sobre a arrecadação mensal do IPTU nas cidades de São Paulo, Rio de Janeiro, Belo Horizonte, Curitiba e Porto Alegre (nos anos de 2004 e 2005) nos permitiram “calibrar” os pesos sazonais da arrecadação total do IPTU (um imposto para o qual a utilização da hipótese de distribuição uniforme ao longo do

24 Como apontam Khair, Araújo e Afonso (2005, p. 6, nota de rodapé 6), o SCN 2003 "não contabiliza o valor [do IR dos servidores estaduais e municipais] retido [na fonte] pelos Estados e municípios, tratando-os como transferências, sob a alegação de que se trata de um imposto de competência federal e não de uma partilha".

25 Mais precisamente, assumimos que o "IR dos Estados e municípios" foi igual a 9.94\% do "IR federal" ao longo de todo o período 1995-1999 (i.e. igual à média observada no período 2000-2003).

26 Ao longo do período 1997-2006 os pesos sazonais do IPVA variaram entre 55,81\% e 58,26\% do total anual no primeiro trimestre, entre $17,05 \%$ e $19,74 \%$ no segundo, entre $13,02 \%$ e $15,09 \%$ no terceiro e entre $8,98 \%$ e $11,41 \%$ no quarto . Os pesos de 1997 (adotados no período 1995:1-1996:4) foram 58,0\%, 19,13\%, 13,53\% e 9,34\%, respectivamente. Dada a regularidade dos dados da arrecadação do IPVA, entretanto o erro derivado dessa aproximação tende a ser pequeno. A variação verificada nos pesos sazonais do ITCMD foi bem maior. Com efeito, no período 1997-2006, esses últimos variaram entre 13,19\% e $20,22 \%$ no primeiro trimestre, entre $20,81 \%$ e $27,73 \%$ no segundo trimestre, entre $20,98 \%$ e $38,58 \%$ no terceiro trimestre e entre 25,56\% e 35,91\% no quarto trimestre. Os pesos de 1997 (adotados no período 1995:1-1996:4), foram 15,92\%, $24,07 \%, 25,59 \%$ e $34,42 \%$, respectivamente. 
ano é claramente inadequada). ${ }^{27}$ Com efeito, nossa série aproximada do IPTU trimestral foi construída aplicando os pesos sazonais encontrados nos referidos dados (a saber, 0,42, 0,22, 0,21 e 0,15 do primeiro ao quarto trimestres, nessa ordem) aos dados da arrecadação anual do IPTU publicados pelo IBGE para o período 1995-2005 (IBGE, 2004a e 2007b) e às nossas estimativas dessa arrecadação para os anos 2006-2007. ${ }^{28}$ Em quarto lugar, os dados de 2006 e 2007 foram calculados supondo-se que o grau de precisão de nossas estimativas (incluindo o IPTU) permaneceu igual ao observado em 2005 (i.e. igual a 92.83\%). Finalmente, em quinto e último lugar, notamos que a hipótese de distribuição uniforme ao longo do ano foi utilizada para o pequeno montante restante de IRPCs e “inteiramente” não explicados.As estimativas obtidas com essas hipóteses estão reproduzidas no Gráfico 2 abaixo e no Apêndice 2 ao final do texto.

\section{Gráfico 2 - Estimativas trimestrais dos impostos sobre a renda a propriedade e o capital (em $\mathrm{R} \$$ bilhões nominais)}

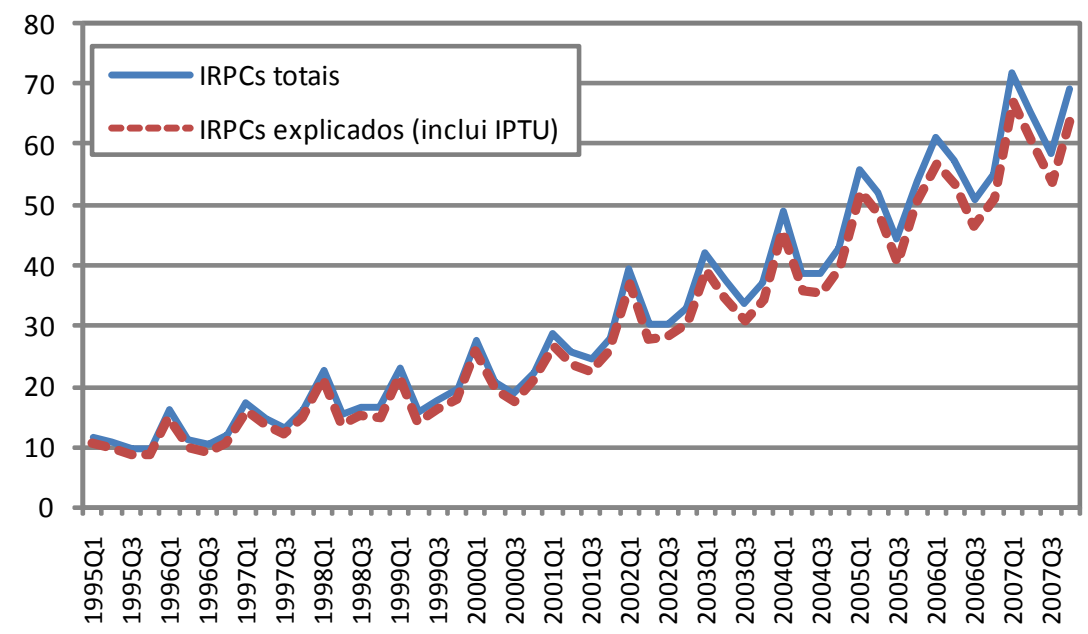

27 Juntas, essas cidades respondem por mais de $1 / 3$ da arrecadação nacional com o IPTU.

28 Tais estimativas foram construídas assumindo-se que a razão entre a arrecadação do IPTU reportada no SCN 2005 e o "total explicado" anual (ver Tabela 6) nos anos de 2006 e 2007 foram iguais à média observada no período 2000 2005 (i.e. 0,072). A aplicação dessa "regra de bolso - que se mostrou capaz de replicar com boa precisão os dados da arrecadação do IPTU reportados nas contas nacionais para o período 2000-2005 (mas não nos anos anteriores, visto que a alíquota da CPMF sofreu aumento significativo em 1999) - foi necessária porque os dados das contas nacionais sobre a arrecadação anual do IPTU são significativamente diferentes tanto dos publicados nas estimativas da carga tributária bruta anual publicadas pela Secretaria da Receita Federal do Brasil quanto dos publicados na pesquisa FINBRA da STN. 
Tabela 6 - Graus de precisão finais das nossas estimativas do agregado dos IRPs e dos impostos sobre o capital (dados em $R \$$ bilhões correntes e em porcentagem)

\begin{tabular}{llccccc}
\hline Ano & Total Anual & $\begin{array}{c}\text { Total } \\
\text { Explicado }\end{array}$ & $\begin{array}{c}\text { Total Explicado }+ \\
\text { IPTU }\end{array}$ & $\begin{array}{c}\text { Total Inteiramente } \\
\text { Inexplicado }\end{array}$ & $\begin{array}{c}\text { Precisão sem } \\
\text { IPTU }\end{array}$ & $\begin{array}{c}\text { Precisão com } \\
\text { IPTU }\end{array}$ \\
\hline 1995 & $40,73 \mathrm{PH}$ & 34,34 & 37,19 & $3.54 \mathrm{PH}$ & $84,31 \% \mathrm{PH}$ & $91,31 \% \mathrm{PH}$ \\
1996 & $48,61 \mathrm{PH}$ & 40,28 & 43,78 & $4.83 \mathrm{PH}$ & $82,88 \% \mathrm{PH}$ & $90,06 \% \mathrm{PH}$ \\
1997 & $60,32 \mathrm{PH}$ & 51,66 & 55,74 & $4.58 \mathrm{PH}$ & $85,64 \% \mathrm{PH}$ & $92,41 \% \mathrm{PH}$ \\
1998 & $70,36 \mathrm{PH}$ & 60,23 & 64,50 & $5.86 \mathrm{PH}$ & $85,60 \% \mathrm{PH}$ & $91,67 \% \mathrm{PH}$ \\
1999 & $75,53 \mathrm{PH}$ & 64,47 & 69,28 & $6.25 \mathrm{PH}$ & $85,36 \% \mathrm{PH}$ & $91,72 \% \mathrm{PH}$ \\
2000 & 89,11 & 76,75 & 82,79 & 6.32 & $86,13 \%$ & $92,91 \%$ \\
2001 & 106,06 & 91,21 & 97,95 & 8.11 & $86,00 \%$ & $92,35 \%$ \\
2002 & 132,43 & 115,70 & 122,94 & 9.49 & $87,37 \%$ & $92,83 \%$ \\
2003 & 149,99 & 129,69 & 138,77 & 11.22 & $86,47 \%$ & $92,52 \%$ \\
2004 & 168,55 & 145,67 & 156,18 & 12.37 & $86,43 \%$ & $92,66 \%$ \\
2005 & 205,72 & 177,78 & 190,98 & 14.74 & $86,42 \%$ & $92,83 \%$ \\
2006 & $224,03 \mathrm{PH}$ & 194,02 & $207,98 \mathrm{PH}$ & $16,05 \mathrm{PH}$ & $86,60 \% \mathrm{PH}$ & $92,83 \% \mathrm{PH}$ \\
2007 & $264,85 \mathrm{PH}$ & 229,37 & $245,87 \mathrm{PH}$ & $18,98 \mathrm{PH}$ & $86,60 \% \mathrm{PH}$ & $92,83 \% \mathrm{PH}$ \\
\hline
\end{tabular}

Fonte: Elaboração dos autores com base em IBGE (2004ae 2007b), STN (2007a e 2007b) e nas séries mensais do IPVA e do ITCMD disponíveis no IPEADATA (ver Apêndice 1).

Nota: PH indica dado "formalmente indisponível mas obtido por hipótese". ${ }^{29}$

\section{ESTIMANDO OS “OUTROS IMPOSTOS LIGADOS À PRODUÇÃO” TRIMESTRAIS}

O último componente da carga tributária bruta trimestral a ser estimado é também o menos importante do ponto de vista quantitativo. Com efeito, dados (da tabela sinótica 20) do SCN 2005 mostram que os "outros impostos ligados à produção" (OILPs) responderam por menos de $4 \%$ da carga tributária bruta total no período 2000-2005. Ademais, a parcela dos OILPs federais nos OILPs totais é bastante inferior à observada nos demais componentes da CTBB (ver Tabela 7), de modo que a precisão de nossas estimativas (baseadas apenas em dados federais) também se mostrou menor nesse caso (ver Tabela 8).

De todo modo, cumpre notar que foi conveniente para os nossos propósitos dividir os OILPs totais em "OILPs sobre a folha de pagamento" e "demais OILPs" (tal como ocorre no SCN 2005). Com efeito, o grau de precisão de nossas estimativas do primeiro grupo (composto apenas por impostos federais - ver Apêndice 1) chega a $100 \%$ em vários anos (ver Tabela 8) sendo, portanto, muito superior ao obtido com o segundo grupo (composto majoritariamente por impostos estaduais e municipais).

29 Os dados anteriores a 2000 foram obtidos no SCN 2003 (IBGE, 2004a - tabela sinótica 26) - que considera os "impostos sobre o capital" como parte dos "impostos sobre a renda e a propriedade". Esses dados foram ajustados para levar em conta o fato de que o IR de Estados e municípios não era computado como IRP no SCN 2003 - ver nota 23. Os dados posteriores a 2000 (inclusive) foram obtidos no SCN 2005 (IBGE 2007b - tabela sinótica 20) somando os "impostos sobre a renda e a propriedade" com os "impostos sobre o capital". 
Tabela 7 - Arrecadação dos “outros impostos ligados à produção" por entes da Federação (em $\mathrm{R} \$$ bilhões correntes)

\begin{tabular}{lrrr}
\hline Ano & Total & \multicolumn{1}{c}{ Federal } & Estadual e Municipal \\
\hline 1995 & 8,66 & $5,50(63,52 \%)$ & $3,16(36,48 \%)$ \\
1996 & 10,42 & $6,33(60,79 \%)$ & $4,09(39,21 \%)$ \\
1997 & 11,53 & $6,88(59,69 \%)$ & $4,65(40,31 \%)$ \\
1998 & 12,92 & $7,15(55,32 \%)$ & $5,77(44,68 \%)$ \\
1999 & 12,01 & $6,84(56,99 \%)$ & $5,16(43,01 \%)$ \\
2000 & 12,24 & $7,44(60,76 \%)$ & $4,80(39,24 \%)$ \\
2001 & 15,08 & $8,26(54,77 \%)$ & $6,82(45,23 \%)$ \\
2002 & 18,04 & $9,33(51,74 \%)$ & $8,71(48,26 \%)$ \\
2003 & 21,27 & $9,97(46,86 \%)$ & $11,30(53,14 \%)$ \\
2004 & 24,95 & $11,71(46,92 \%)$ & $13,24(53,08 \%)$ \\
2005 & 27,98 & $14,40(51,48 \%)$ & $13,57(48,52 \%)$ \\
\hline
\end{tabular}

Fonte: Elaboração dos autores com base em IBGE (2004a e 2007a).

Nota: Dados anteriores a 2000 são do SCN 2003 (IBGE, 2004a) ajustados para se tornarem compatíveis com os dados do SCN 2005 30. Dados de 2000 até 2005 são do SCN 2005.

Tomados em conjunto, os resultados das Tabelas 7 e 8 indicam que conseguimos explicar praticamente todos os OILPs federais e, portanto, cerca de metade dos OILPs totais (ver Apêndice 1 para a composição precisa de nossas estimativas). Entretanto, algumas hipóteses simplificadoras não triviais tiveram que ser feitas quando da construção de nossa série de OILPs "explicados" trimestrais, a saber: (i) assumimos que a sazonalidade da série das contribuições do sistema "S" foi idêntica à observada na série da arrecadação do salário-educação; ${ }^{31}$ (ii) assumimos que a sazonalidade da arrecadação do salário-educação em 1995 foi igual à observada em 1996; ${ }^{32}$ (iii) assumimos que a razão entre as arrecadações anuais das contribuições para o sistema "S" e do salário-educação em 2006 e 2007 foi igual à observada em $2005,{ }^{33}$ e (iv) assumimos que o grau de precisão de nossas estimativas em 2006 e 2007 foi igual ao observado em 2005. ${ }^{34}$ Finalmente, notamos que, por não termos tido acesso a quaisquer informações sobre a sazonalidade dos OILPs "não explicados", adotamos a hipótese de que esses últimos se distribuíram uniformemente ao longo dos anos. As estimativas "finais" obtidas com essas hipóteses estão reproduzidas no Gráfico 3 e no Apêndice 2 ao final do texto.

30 Os dados do SCN 2003 incluíam entre os OILPs as contribuições para o PIS-PASEP (reclassificadas como "contribuições previdenciárias" no SCN 2005), a CIDE-Combustíveis e a COFINS (ambas reclassificadas como impostos sobre produtos" no SCN 2005).

31 Até onde sabemos, não existem dados de alta freqüência para a arrecadação do Sistema "S" a disposição dos cidadãos brasileiros na Internet.Dadas as similaridades entre as "bases de arrecadação" de ambos os tributos, acreditamos que os erros gerados por essa hipótese simplificadora sejam de pequena ordem.

32 Os dados da arrecadação do salário-educação no ano de 1995 disponíveis em STN (2007a) estão claramente equivocados.

33 Note-se que os números divulgados pelo IBGE (tanto no SCN 2003 quanto no SCN 2005) sobre a arrecadação anual com o "sistema S" diferem consideravelmente dos divulgados pelo Secretaria da Receita Federal do Brasil - de modo que preferimos usar o procedimento acima a reportar o dado da SRFB para a arrecadação do "sistema S" em 2006 (SRFB, 2007).

34 A fim de obtermos valores para os OILPs totais nesses anos. 
Tabela 8 - Graus de precisão das estimativas finais dos “OILPs” (dados em R\$ bilhões correntes e em \%)

\begin{tabular}{ccccccccc}
\hline Ano & $\begin{array}{c}\text { OlLPs "sobre } \\
\text { a folha de pag" } \\
\text { estimados } \\
\text { (inclui Sist. "S") } \\
(1)\end{array}$ & $\begin{array}{c}\text { OlLPs } \\
\text { "sobre a } \\
\text { folha de pag" } \\
\text { efetivos } \\
(2)\end{array}$ & $\begin{array}{c}\text { Precisão } \\
(3)\end{array}$ & $\begin{array}{c}\text { Demais } \\
\text { OlLPs } \\
\text { federais } \\
\text { estimados } \\
(4)\end{array}$ & $\begin{array}{c}\text { Demais } \\
\text { OlLPs } \\
\text { federais } \\
\text { efetivos } \\
(5)\end{array}$ & $\begin{array}{c}\text { OlLPs não } \\
\text { explicados } \\
\text { totais (inclui } \\
\text { Estados e } \\
\text { municipios) } \\
(6)\end{array}$ & $\begin{array}{c}\text { OlLPs } \\
\text { totais } \\
(7)\end{array}$ & $\begin{array}{c}\text { Precisão } \\
\text { final } \\
{[(1)+(4)] /(7)}\end{array}$ \\
\hline 1995 & 4,73 & 4,73 & $100 \%$ & 0,50 & 0,77 & 3,43 & 8,66 & $60,42 \%$ \\
1996 & 5,56 & 5,56 & $100 \%$ & 0,53 & 0,77 & 4,33 & 10,42 & $58,47 \%$ \\
1997 & 5,93 & 5,93 & $100 \%$ & 0,70 & 0,95 & 4,90 & 11,53 & $57,52 \%$ \\
1998 & 5,46 & 5,46 & $100 \%$ & 1,34 & 1,69 & 6,12 & 12,92 & $52,67 \%$ \\
1999 & 5,19 & 5,19 & $100 \%$ & 1,32 & 1,65 & 5,51 & 12,01 & $54,28 \%$ \\
2000 & 5,90 & 5,91 & $99.78 \%$ & 1,60 & 1,53 & 4,74 & 12,24 & $61,26 \%$ \\
2001 & 6,52 & 6,72 & $97,02 \%$ & 1,81 & 1,54 & 6,75 & 15,08 & $55,26 \%$ \\
2002 & 7,41 & 7,81 & $94,83 \%$ & 1,43 & 1,52 & 9,20 & 18,04 & $48,98 \%$ \\
2003 & 8,21 & 8,21 & $100 \%$ & 1,71 & 1,75 & 11,35 & 21,27 & $46,64 \%$ \\
2004 & 9,51 & 9,51 & $100 \%$ & 2,16 & 2,19 & 13,28 & 24,95 & $46,76 \%$ \\
2005 & 11,42 & 11,43 & $99.98 \%$ & 2,82 & 2,97 & 13,73 & 27,98 & $50,93 \%$ \\
2006 & $13,79 \mathrm{PH}$ & $13,79 \mathrm{PH}$ & $100 \% \mathrm{PH}$ & 3,18 & $3,35 \mathrm{PH}$ & $16,35 \mathrm{PH}$ & $33,31 \mathrm{PH}$ & $50,93 \% \mathrm{PH}$ \\
2007 & $14,25 \mathrm{PH}$ & $14,25 \mathrm{PH}$ & $100 \% \mathrm{PH}$ & 3,74 & $3,94 \mathrm{PH}$ & $17,13 \mathrm{PH}$ & $34,90 \mathrm{PH}$ & $50,93 \% \mathrm{PH}$ \\
\hline
\end{tabular}

Fonte: Elaboração dos autores com base em IBGE (2004a e 2007a) e STN (2007a e 2007b).

Nota: PH indicadados “formalmente indisponíveis, mas obtidos por hipótese”. Os dados anteriores a 2000 foram ajustados para se tornarem compatíveis com os dados do SCN 2005.

Gráfico 3 - Estimativas trimestrais dos "outros impostos ligados à produção" (em R $\$$ bilhões nominais)

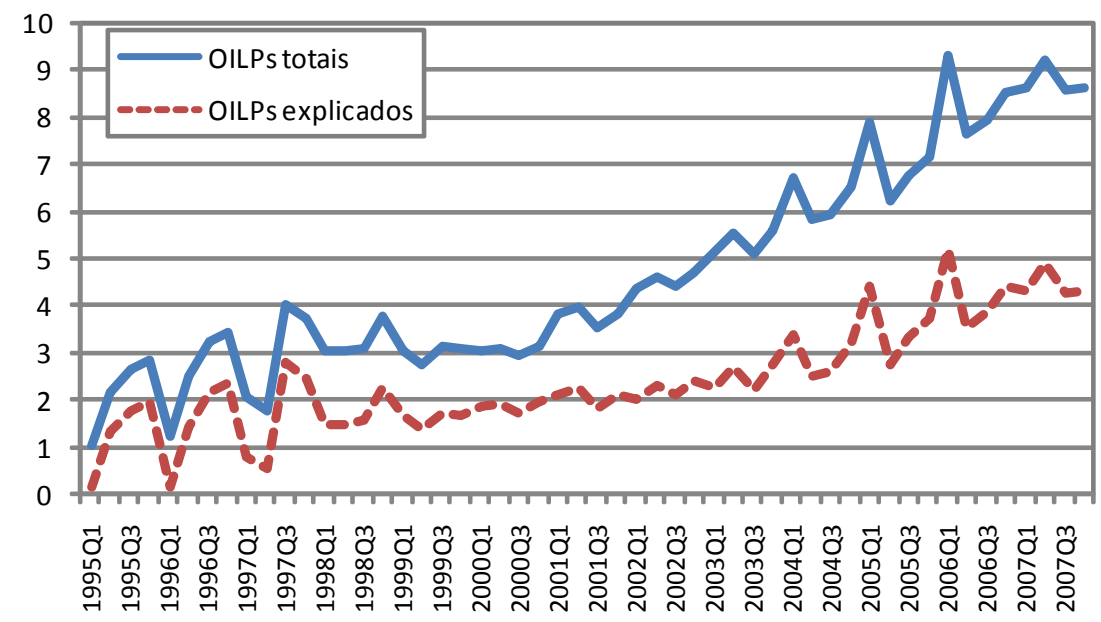




\section{ESTIMATIVAS FINAIS DA CARGA TRIBUTÁRIA BRUTA TRIMESTRAL: PRECISÃO, ROBUSTEZ E UTILIDADE POTENCIAL}

Tendo embarcado em uma tour de force de hipóteses simplificadoras, acrônimos e definições contábeis pouco familiares nas seções anteriores, é natural que o leitor tenha dúvidas sobre a robustez e utilidade potencial das estimativas reportadas nesse trabalho. Ainda que reconheçamos prontamente que nossa metodologia pode ser aperfeiçoada de muitas maneiras (e que torçamos para que outros pesquisadores se interessem em fazê-lo), parece-nos, pois, apropriado apontar alguns méritos dessa última. Mais precisamente, argumentaremos aqui: (i) que o grau de precisão final de nossas estimativas é alto, e (ii) que, após serem submetidas a ajustes sazonais, as mesmas parecem robustas a mudanças nas hipóteses simplificadoras adotadas sobre a sazonalidade das parcelas não explicadas dos vários componentes da carga tributária.

Começamos notando que o fato de termos muita certeza do valor dos impostos sobre produtos (de longe o mais importante componente da CTBB) aumenta significativamente nosso grau de precisão final. ${ }^{35}$ Com efeito, a precisão média das nossas estimativas finais ficou em torno de 92\% nos últimos anos (ver Tabela 9). Isso significa que, na pior das hipóteses da parcela não explicada dos nossos dados ${ }^{36}$ ser arrecadada em um único trimestre "T", nossos números subestimarão o valor efetivo da arrecadação nesse trimestre em pouco menos de $6 \%$ do valor anual da CTBB (ou R \$54,8 bilhões em 2007, o equivalente a 2,14\% do PIB desse ano) e superestimarão os valores efetivos da arrecadação nos três outros trimestres em cerca de $2 \%$ do valor anual da CTBB (ou cerca de R $\$ 18.2$ bilhões em 2007) - ver Gráfico $5 .^{37}$ Naturalmente, não temos qualquer motivo para achar que estamos incorrendo em um viés tão extremo - o ponto aqui é apenas dar uma idéia das magnitudes envolvidas em um caso no qual as hipóteses simplificadoras que fizemos são aproximações obviamente muito ruins da "realidade", por assim dizer.

35 Duas razões nos impedem de ter completa certeza sobre o valor da arrecadação trimestral dos impostos sobre produtos, quais sejam: (i) o fato de a série trimestral divulgada pelo IBGE ser "líquida de subsídios sobre produtos", e (ii) o fato de a série trimestral do IBGE sofrer revisões relativamente freqüentes. Ainda assim, decidimos contar nossa série de impostos sobre produtos como "totalmente explicada", uma vez que os subsídios sobre produtos são muito pequenos como porcentagem dos impostos sobre produtos (e.g. $0.3 \% \mathrm{em} 2004 \mathrm{e} 0.5 \% \mathrm{em} 2005$ ) e que sempre podemos recalcular a CTBB trimestral a partir da divulgação pelo IBGE dos dados "revistos" dos impostos sobre produtos líquidos de subsídios.

36 Excluindo o IPTU, que responde em média por 1.65\% da CTBB anual.

37 Dadas nossas hipóteses especiais sobre a sazonalidade do IPTU e das contribuições previdenciárias de Estados e municípios, a magnitude precisa do viés discutido acima variará levemente dependendo do trimestre escolhido para concentrar a carga inexplicada e mesmo do ano em questão. 


\section{Gráfico 4 - Estimativas trimestrais da CTBB (em $\mathbf{R} \$$ bilhões nominais)}

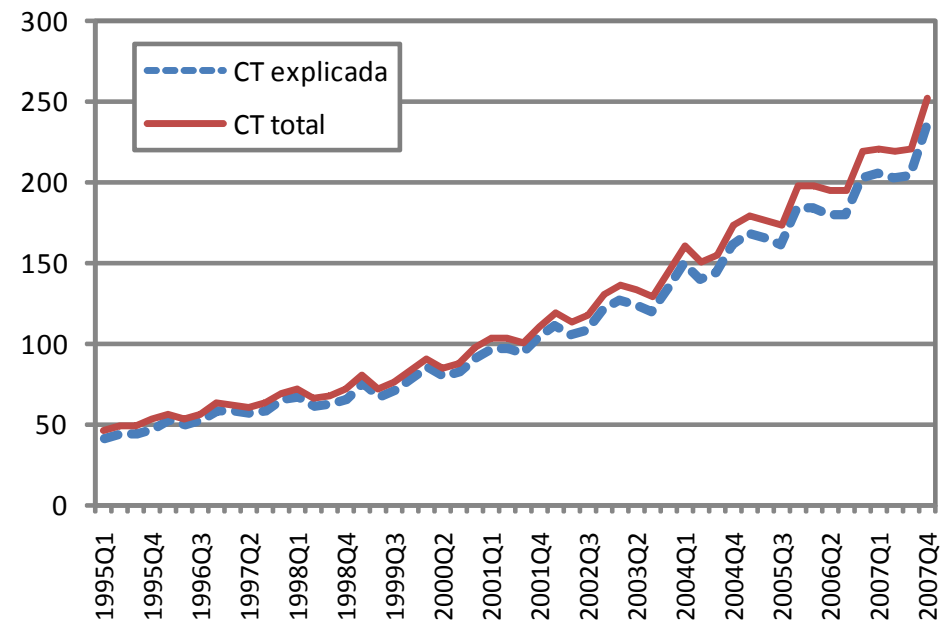

Gráfico 5 - O quão errados podemos estar? (1)

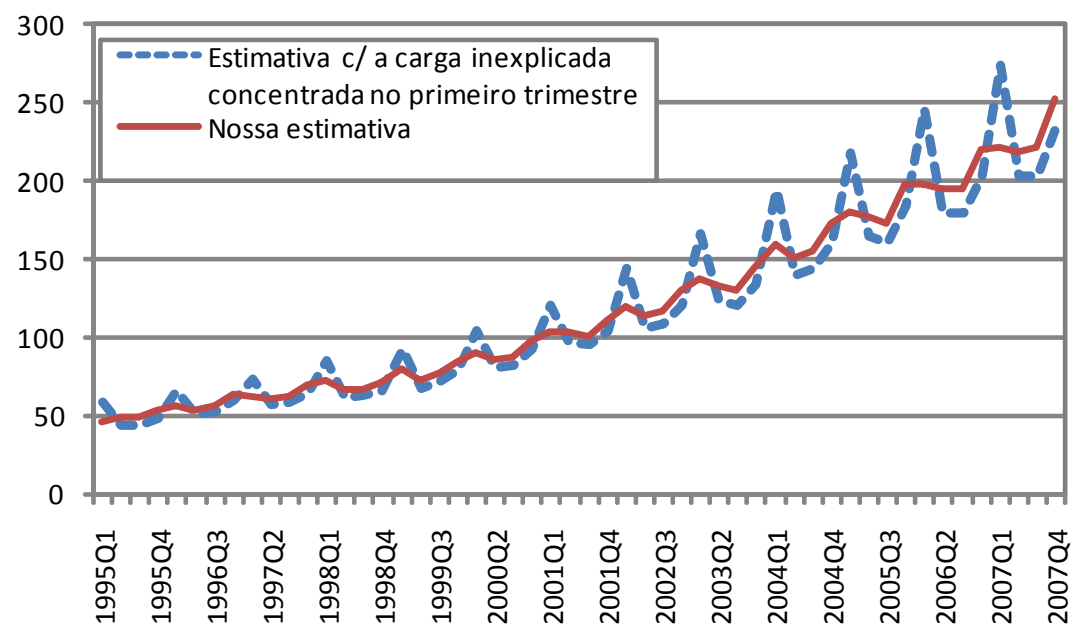


Tabela 9 - Graus de precisão finais (em $R \$$ bilhões correntes) ${ }^{38}$

\begin{tabular}{|c|c|c|c|c|c|c|c|c|c|}
\hline \multirow[t]{2}{*}{ Ano } & \multirow[t]{2}{*}{ IPs } & \multicolumn{2}{|c|}{ OILPs } & \multicolumn{2}{|c|}{ Cont. Prev. } & \multicolumn{2}{|c|}{ IRPCs } & \multicolumn{2}{|c|}{ Total } \\
\hline & & Efet. & Explicado & Efet. & Explicado & Efet. & Explicado & Efet. & Explicado \\
\hline 1995 & 89,57 & 8,66 & $\begin{array}{c}5,23 \\
(60,42 \%)\end{array}$ & $54,03^{39}$ & $\begin{array}{l}43,48 \\
(80,48 \%)\end{array}$ & 40,73 & $\begin{array}{l}37,19 \\
(91,31 \%)\end{array}$ & 192,99 & $\begin{array}{l}175,48 \\
(90,93 \%)\end{array}$ \\
\hline 1996 & 101,11 & 10,42 & $\begin{array}{c}6,09 \\
(58,46 \%)\end{array}$ & 66,00 & $\begin{array}{l}62,15 \\
(94,17 \%)\end{array}$ & 48,61 & $\begin{array}{l}43,78 \\
(90,06 \%)\end{array}$ & 226,13 & $\begin{array}{l}213,13 \\
(94,25 \%)\end{array}$ \\
\hline 1997 & 108,52 & 11,53 & $\begin{array}{c}6,63 \\
(57,53 \%)\end{array}$ & 71,84 & $\begin{array}{l}66,85 \\
(93,06 \%)\end{array}$ & 60,32 & $\begin{array}{l}55,74 \\
(92,41 \%)\end{array}$ & 252,21 & $\begin{array}{l}237,74 \\
(94,27 \%)\end{array}$ \\
\hline 1998 & 113,28 & 12,92 & $\begin{array}{c}6,80 \\
(52,66 \%)\end{array}$ & 77,80 & $\begin{array}{l}71,54 \\
91,96 \%)\end{array}$ & 70,36 & $\begin{array}{l}64,50 \\
(91,67 \%)\end{array}$ & 274,36 & $\begin{array}{l}256,13 \\
(93,35 \%)\end{array}$ \\
\hline 1999 & 137,16 & 12,01 & $\begin{array}{c}6,51 \\
(54,26 \%)\end{array}$ & 85,37 & $\begin{array}{l}79,67 \\
(93,32 \%)\end{array}$ & 75,53 & $\begin{array}{l}69,28 \\
(91,72 \%)\end{array}$ & 310,06 & $\begin{array}{l}292,62 \\
(94,38 \%)\end{array}$ \\
\hline 2000 & 161,95 & 12,24 & $\begin{array}{c}7,49 \\
(61,24 \%)\end{array}$ & 94,84 & $\begin{array}{l}87,20 \\
(91,94 \%)\end{array}$ & 89,11 & $\begin{array}{l}82,79 \\
(92,91 \%)\end{array}$ & 358,13 & $\begin{array}{l}339,43 \\
(94,78 \%)\end{array}$ \\
\hline 2001 & 186,03 & 15,08 & $\begin{array}{c}8,33 \\
(55,25 \%)\end{array}$ & 107,78 & $\begin{array}{l}98,45 \\
(91,34 \%)\end{array}$ & 106,06 & $\begin{array}{c}97,95 \\
(92,35 \%)\end{array}$ & 414,95 & $\begin{array}{l}390,76 \\
(94,17 \%)\end{array}$ \\
\hline 2002 & 204,98 & 18,04 & $\begin{array}{c}8,84 \\
(48,98 \%)\end{array}$ & 122,63 & $\begin{array}{l}109,09 \\
(88,96 \%)\end{array}$ & 132,43 & $\begin{array}{l}122,94 \\
(92,83 \%)\end{array}$ & 478,09 & $\begin{array}{l}445,85 \\
(93,26 \%)\end{array}$ \\
\hline 2003 & 229,67 & 21,27 & $\begin{array}{c}9,92 \\
(46,64 \%)\end{array}$ & 141,33 & $\begin{array}{l}125,68 \\
(88,92 \%)\end{array}$ & 149,99 & $\begin{array}{l}138,77 \\
(92,52 \%)\end{array}$ & 542,27 & $\begin{array}{l}504,04 \\
(92,95 \%)\end{array}$ \\
\hline 2004 & 276,08 & 24,95 & $\begin{array}{c}11,66 \\
(46,75 \%)\end{array}$ & 167,68 & $\begin{array}{l}148,20 \\
(88,38 \%)\end{array}$ & 168,55 & $\begin{array}{l}156,18 \\
(92,66 \%)\end{array}$ & 637,25 & $\begin{array}{l}592,12 \\
(92,92 \%)\end{array}$ \\
\hline 2005 & 306,55 & 27,98 & $\begin{array}{l}14,25 \\
(50,91 \%)\end{array}$ & 186,11 & $\begin{array}{l}165,01 \\
(88,66 \%)\end{array}$ & 205,72 & $\begin{array}{l}190,98 \\
(92,83 \%)\end{array}$ & 726,36 & $\begin{array}{l}676,78 \\
(93,17 \%)\end{array}$ \\
\hline $2006^{*}$ & 333,15 & 33,31 & $\begin{array}{l}16,96 \\
(50,92 \%)\end{array}$ & 215,75 & $\begin{array}{l}186,51 \\
(86,45 \%)\end{array}$ & 224,03 & $\begin{array}{l}207,98 \\
(92,83 \%)\end{array}$ & 806,24 & $\begin{array}{l}744,61 \\
(92,36 \%)\end{array}$ \\
\hline $2007^{*}$ & 369,80 & 34,90 & $\begin{array}{l}17,78 \\
(50,93 \%)\end{array}$ & 243,26 & $\begin{array}{l}210,29 \\
(86,45 \%)\end{array}$ & 264,85 & $\begin{array}{l}245,87 \\
(92,83 \%)\end{array}$ & 912,80 & $\begin{array}{l}843,73 \\
(92,43 \%)\end{array}$ \\
\hline
\end{tabular}

Fonte: Elaboração dos autores com base em IBGE (2007a e 2007d) e nas tabelas anteriores.

Claro está que a mera possibilidade de erros da magnitude acima é, por si só, preocupante. Cumpre notar, entretanto, que, mesmo no caso da parcela não explicada dos dados exibir um padrão sazonal muito diferente do assumido acima, o viés de (medidas sazonalmente ajus$\operatorname{tadas}^{40}$ das) nossas estimativas será bastante modesto, desde que o referido padrão sazonal seja relativamente estável. Os dois gráficos a seguir visam ilustrar esse ponto. O primeiro deles mostra que obtemos resultados muito semelhantes quando ajustamos sazonalmente as quatro séries obtidas, quando assumimos que as cargas não explicadas são integralmente arrecadadas

38 Os valores "explicados" acima incluem a arrecadação do IPTU (que foi calibrada com base na sazonalidade observada nas principais capitais do País) e a arrecadação do "Sistema S" (que foi calibrada com base na sazonalidade observada na arrecadação do "salário-família"). Entretanto, a precisão total de nossas estimativas permaneceria acima/próxima de $90 \%$ mesmo que esse não fosse o caso.

39 O valor das CPs em 1995 difere do reportado na Tabela 4, porque optamos por utilizar o dado da SRFB para a arrecadação dos CIOPs excluindo PIS-PASEP nesse ano (ver Seção 3).

40 No caso, o método X-11 multiplicativo disponível no software E-Views. Para detalhes, ver Quantitative Micro Software (2001). 
em um trimestre apenas (chamamos de "série extrema 1" a série que concentra a carga não explicada no primeiro trimestre, de "série extrema 2", a que concentra a carga não explicada no segundo trimestre e assim por diante). O segundo mostra que o viés das nossas estimativas com ajuste sazonal aumenta consideravelmente quando assumimos que o padrão sazonal das séries muda radicalmente ao longo da amostra. ${ }^{41}$ Ainda que não se constituam em provas formais, os exemplos abaixo parecem indicar que, após serem ajustadas sazonalmente, nossas estimativas da carga tributária trimestral serão muito viesadas apenas no caso improvável da carga não explicada oscilar entre padrões sazonais "extremos" diferentes.

\section{Gráfico 6 - O quão errados podemos estar (2)}

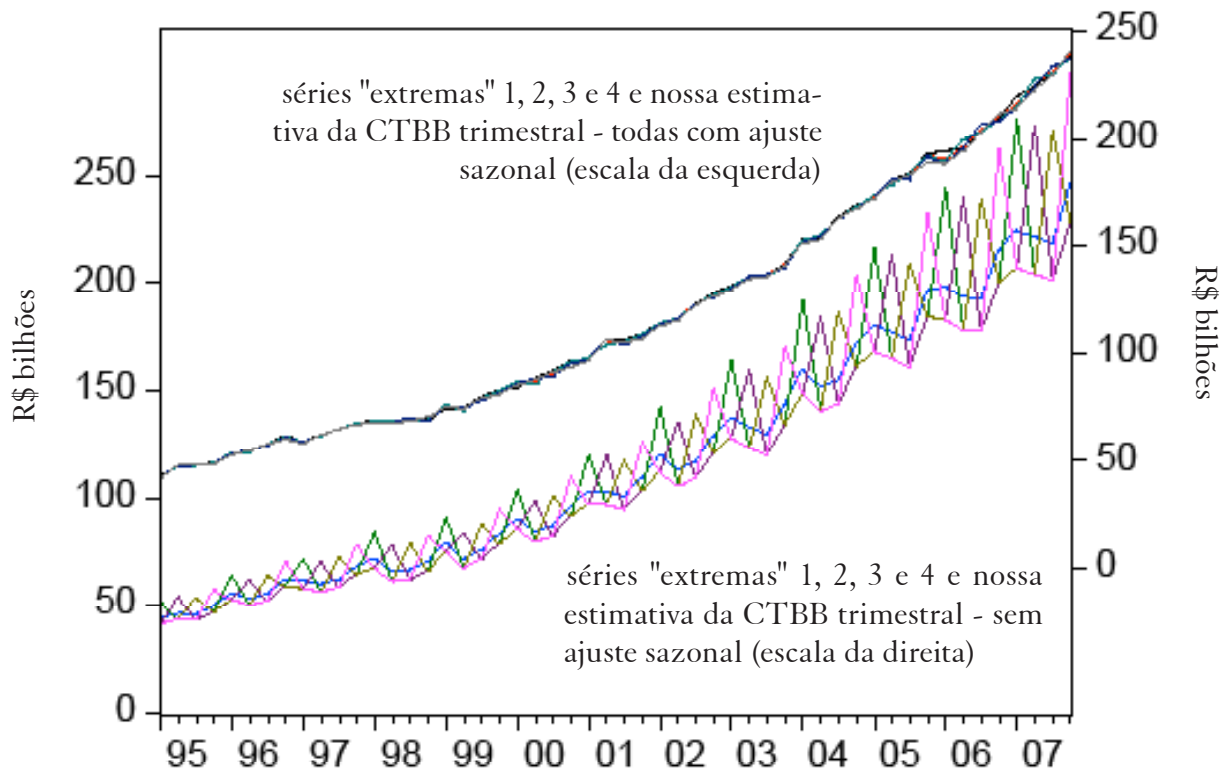

41 Nossa série "quebrada” foi construída juntando arbitrariamente “pedaços” das séries “extremas” utilizadas no Gráfico 6 (mais precisamente, a série "extrema 1" foi utilizada de 1995:1-1996:4, a série "2" de 1997:1-1999:4, a série "3" de 2000:1-2002:4 e a série “4” de 2003:1-2006:4). O ponto desse exercício é apenas o de mostrar ao leitor um caso em que a metodologia de estimação adotada nesse trabalho gera resultados distantes da realidade. 


\section{Gráfico 7 - O quão errados podemos estar (3)}

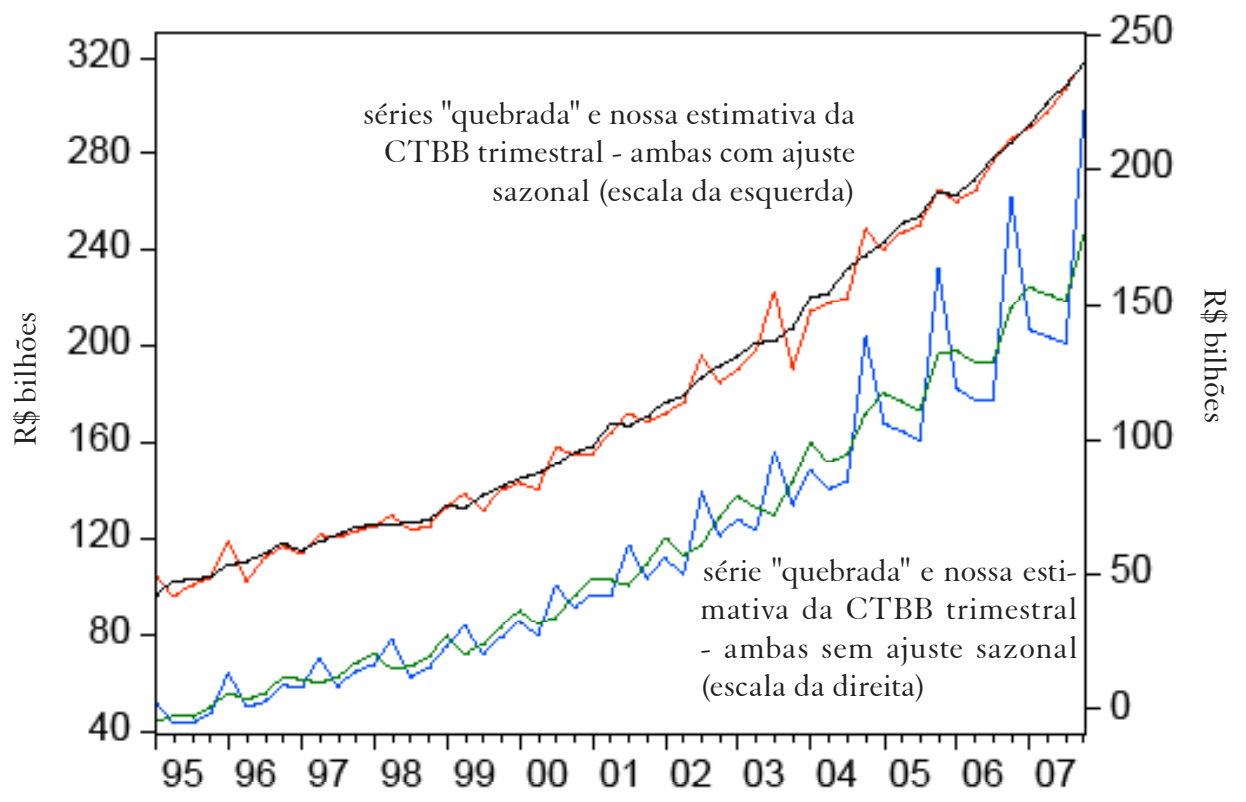

\section{Notas FinAIS}

Este artigo apresentou (uma metodologia de construção de) estimativas da CTBB trimes-

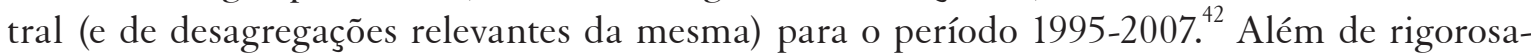
mente basea-das na metodologia oficial das contas nacionais (IBGE, 2004b e IBGE, 2007c) e em dados oficiais de diversas fontes, nossas estimativas parecem razoavelmente robustas ao relaxamento de várias das hipóteses simplificadoras (ainda que plausíveis a priori) adotadas na construção das mesmas.

Cabe frisar, entretanto, que as estimativas apresentadas nesse trabalho são aproximações admitidamente imperfeitas da realidade - em grande parte porque a precariedade das bases de dados existentes fez com que tivéssemos que adotar um número relativamente grande de hipóteses não triviais na construção das mesmas. Porém, mesmo reconhecendo que há considerável espaço para aperfeiçoamento das estimativas apresentadas neste artigo - e torcendo para que outros pesquisadores se interessem em aperfeiçoá-las - acreditamos ter tomado cuidados suficientes para garantir que a "informação" contida nas mesmas supere em muito o "ruído" introduzido por possíveis erros de estimação. Nesse sentido, acreditamos que, se utilizadas com suficiente critério, as estimativas apresentadas neste trabalho podem ser úteis em análises econométricas e/ou históricas sobre o período em questão.

42 Entretanto, nossas estimativas para 2006 e 2007 são preliminares, dado que - até abril de 2008, quando a versão final desse artigo ficou pronta - o IBGE não tinha publicado os dados oficiais da CTBB de 2006. 


\section{REFERÊNCIAS}

AFONSO, A; SCHUKNECHT, L; TANZI, V. Public sector efficiency: evidence for new eu member states and emerging markets. Frankfurt: Banco Central Europeu, 2006. (Texto para Discussão, n. 581).

AFONSO, J. R, ARAÚJO, E. A.; KHAIR, A. Carga tributária - mensuração e impacto sobre o crescimento. Revista de Economia \& Relações Internacionais, v. 4, n. 7, p. 27-42. S. Paulo: Fundação Armando Álvares Penteado FAAP, julho 2005.

AFONSO, J. R.; MEIRELLES, B. B. Carga tributária global no Brasil, 2000-2005: cálculos revisitados. Núcleo de Estudos de Políticas Públicas/Unicamp, 2006.Mimeo.

ARROW, K. J. A difficulty in the concept of social welfare. Journal of Political Economy, v. 58, p. 328- 346, 1950.

Social Choice and Individual Values. Nova Iorque: Wiley, 1951.

CAIXA ECONÔMICA FEDERAL. Relatório da administração. Vários números. Brasília, DF.

COUTINHO, R. Abrindo o debate: política social em tempos de crise. In: PELLIANO, A. (Org.) Desafios e perspectivas da política social. Brasília-DF: IPEA, 2006. (Texto para Discussão, n. 1248)

DELFIM NETTO, A. Prefácio. In: LANGONI, C. G. Distribuição de renda e desenvolvimento econômico no Brasil. Rio de Janeiro: Expressão e Cultura, 1973.

IBGE. Sistema de Contas Nacionais: Brasil 2003. Rio de Janeiro, RJ, 2004a. (Contas Nacionais, n.12). $200 \overline{4}$ b.

. Sistema de Contas Nacionais: Brasil. Série Relatórios Metodológicos, v. 24. Rio de Janeiro,

Sistema de Contas Nacionais: Brasil 2004-2005. Coordenação de Contas Nacionais. Rio de Janeiro, 2007a.

Sistema de Contas Nacionais: Brasil 2000-2005. Coordenação de Contas Nacionais. Rio de Janeiro, $2007 \mathrm{~b}$.

. Notas metodológicas da nova série do Sistema de Contas Nacionais (SCN) referência 2000 (versão para informação e comentários). Coordenação de Contas Nacionais. Rio de Janeiro, 2007c.

. Contas nacionais trimestrais: indicadores de volume e valores correntes. Coordenação de Contas Nacionais. Rio de Janeiro, 2007d.

MARGLIN, S.; BHADURI, A. Unemployment and the real wage: the economic basis for contesting political ideologies. Cambridge Journal of Economics, v. 4, p. 375-393, 1990.

MINISTÉRIO DA PREVIDÊNCIA SOCIAL. Anuário estatístico da previdência social 2006. Brasília, 2007.

ORGANIZAÇÃO DAS NAÇÕES UNIDAS. System of national accounts 1993. Nova York, 1993.

PERSSON, T.; TABELLINI, G. Political economics: explaining economic policy (zeuthen lectures). Cambridge: MIT Press, 2000.

. Political economics and public finance. In: AUERBACH, A. J.; FELDSTEIN, M. (Ed.). Handbook of Public Economics, v. 3, Nova York: Elsevier Science, 2002.

QUANTITATIVE MICRO SOFTWARE. E-Views 4 users' guide. Irvine, Califórnia, 2001.

RIBEIRO, M. Eficiência do gasto público na América Latina: uma análise comparativa a partir de um modelo semi-paramétrico com estimativa em dois estágios. Brasília: Coordenação de Finanças Públicas/ IPEA, 2007. Mimeo.

ROMER, D. Advanced macroeconomics, Nova York: McGraw-Hill, 1996. 
SECRETARIA DA RECEITA FEDERAL DO BRASIL. Carga tributária no Brasil 1998. Brasília, 1999. (Texto para Discussão, n. 4).

. Carga tributária no Brasil 2006. Brasília, 2007. (Estatísticas Tributárias, n. 13)

SECRETARIA DO TESOURO NACIONAL. Demonstração da execução das receitas de contribuições orçamentos fiscal e da seguridade social. Brasília, 2007a.

. Demonstração da execução das receitas tributárias - orçamentos fiscal e da seguridade social. Brasília, 2007b. . Estados e municípios: indicadores fiscais e de endividamento. Brasília, 2007c.

STONE, R. Nobel memorial lecture 1984: the accounts of society. Journal of Applied Econometrics, v. 1, n. 1, p. 5-28, 1986.

TANZI, V.; ZEE, H. Tax policy for emerging markets: developing countries. Washington-DC: International Monetary Fund, 2000. (IMF Working Paper 00/35).

VELLOSO, R. Escancarando o problema fiscal: é preciso controlar o gasto não-financeiro obrigatório da União. Rio de Janeiro: Instituto Nacional de Altos Estudos, 2006. (Estudos e Pesquisas, n. 159). 


\section{APÊNDICE 1 - COMPOSIÇÃO PRECISA DOS COMPONENTES ESTIMADOS DA CTBB}

O propósito desse apêndice é detalhar os dados efetivamente utilizados na construção das estimativas dos componentes da carga tributária bruta discutidas nas Seções 3-5 anteriores. Como mencionado no texto principal, as mesmas são baseadas quase que exclusivamente no Apêndice 8 de IBGE (2004b), mas achamos por bem apresentar uma lista detalhada para dirimir possíveis ambigüidades criadas pelos fatos de que: (i) vários impostos e contribuições foram criados e/ou desapareceram no período 1995-2007; (ii) o nível de detalhe/desagregação dos dados da STN variou consideravelmente ao longo desse período, e (iii) a revisão das contas nacionais em março de 2007 reclassificou vários impostos importantes. Salvo menção em contrário, os dados abaixo foram obtidos em STN (2007a) e incluem receitas com programas de recuperação fiscal.

\section{A.1.1 Impostos sobre a renda e o patrimônio}

Contribuição Social sobre o Lucro Líquido de Pessoas Jurídicas

Imposto de Renda - (STN 2007b - todas as desagregações disponíveis em cada ano).

ITCMD - (IPEADATA, série reconstruída para trás a partir de 1996:4).

IPVA - (IPEADATA, série reconstruída para trás a partir de 1996:4).

CPMF - os dados de 1995 estão disponíveis em STN (2007b), enquanto os dados de 1997-2007 estão disponíveis em STN (2007a). A contribuição não foi arrecadada em 1996.

\section{A.1.2 Contribuições previdenciárias}

\section{A.1.2.1 - Regime geral (INSS e PIS-PASEP apenas) ${ }^{43}$}

Segurados - autônomos (entre 1995-2004)

Contribuições do segurado - assalariado

Contribuição de empresas sobre segurados assalariados

Simples (a partir de 1999)

Empresas - espetáculos esportivos (a partir de 1997)

Contribuição sobre produção rural

Contribuição em regime de parcelamento e débitos

Seguro de acidente do trabalho

Reclamatória trabalhista (a partir de 2002)

Contribuição débitos / parcelamento - município (entre 1996 e 2005)

43 Não inclui a arrecadação bruta do FGTS (obtida no IPEADATA e em vários números do relatório de administração da Caixa Econômica Federal) - que deve, portanto, ser adicionada ao total de das contribuições acima. 
Outras contribuições previdenciárias (até 2006)

Contr. de serv. e entidades p/ benef. do RGPS. (entre 1995-1998)

Outras contrib. urbanas (entre 1995 - 2001)

Contr. empres. de clubes de futebol profis. (em 1996)

Seguro de acidente de trabalho - SAT (entre 1997 e 2001)

Outras contribuições rurais (entre 1997 e 1999)

Dívida ativa previdenciária (entre 2000 e 2001)

Contribuição previd. do segurado especial (a partir de 2003)

Contribuição previd. do seg. obrig-emp. domésticos (a partir de 2003)

Contr. prev. dos orgãos do poder público (a partir de 2003) ${ }^{44}$

Contr. prev. das entidades filantrópicas (a partir de 2003)

Contr. prev. -ret. s/nota fiscal- sub-rogação (a partir de 2003)

Arrecadação FIES - certificados financ. tesouro nacional (a partir de 2003)

Arrecadação FNS- certificados financ. tes. nac. (a partir de 2003)

Contr. prev. na forma de dep. jud., rec. e custas (a partir de 2003)

Contribuição previd. do segurado facultativo (a partir de 2003)

Prog. recup. fiscal/parc. esp. -empr/trab; seg. soc (a partir de 2005)

Contr. prev. segurado obrig. -contr. indiv. (a partir de 2005)

Receita de arrecadação cont. para o financiamento do PIS/PASEP

\section{A.1.2.2 - Funcionalismo público}

Contr. plano de seguridade social do servidor (até 2002)

Montepio Civil (STN, 2007b, até 2005)

Pensões Militares (STN,2007b, até 1998)

Contr. Para Custeio das Pensões Militares (desde 1998)

Contr. Patronal - Ativo Civil (2003 e 2004)

Contr. de Servidor Ativo Civil (2003 e 2004)

Contr. Patronal P/ Plano Seg. Social Serv. Inativo (2004)

Contr. de Servidor P/ Plano Seg. Social Serv. Inativo (2004)

Contr. Patronal P/ Plano Seg. Social - Pensionistas (2004)

Contr. De Servidor P/ Plano Seg. Social Serv. - Pensionistas (2004)

Contr. Patr. P/Plano Segur. Soc. Serv. Público (2005)

Contr. Patr. P/ Regime Próprio de Previdência (2007)

Contr. Serv. P/Plano Segur. Soc. Serv. Ativo (a partir de 2005)

44 Aparentemente essa variável passa a incorporar a (ou, pelo menos boa parte da) variável "contr. de servidor ativo civil" (ver A.1.2.2) a partir de 2005. 
Contr. do Servidor p/Plano Seg Social - Inat. (a partir de 2005)

Contr. P/Plano Seg. Social Serv. - Pensionista (a partir de 2005)

\section{A.1.3 - Outros impostos ligados à produção}

A.1.3.1 Impostos sobre a folha de pagamento ${ }^{45}$

Contribuição do salário-educação

Contribuição para o ensino aeroviário

Contribuição para o desenvolvimento do ensino profissional marítimo

Contribuição para o fundo de saúde (até 2003)

Contribuição ao programa de ensino fundamental (até 2004)

Contribuição industrial rural

Adicional à contribuição previdenciária

\section{A.1.2. Outros impostos e taxas sobre a produção ${ }^{46}$}

Taxa de fiscalização de serviço de energia elétrica (STN, 2007b - desde 1998)

Taxa de fiscalização das telecomunicações (STN, 2007b)

Taxa de fiscalização da vigilância sanitária (STN, 2007b - desde 2000)

Taxa de fiscalização do merc. seg. capit. e prev. priv. aberta (STN, 2007b)

Taxa de fiscalização do merc. de fisc. do merc. titul. e val. mobiliários (STN, 2007b)

Taxa de serviços sdministrativos - Tsa (STN, 2007b - desde 2002)

Taxa de controle e fiscalização ambiental (STN, 2007b - desde 2001)

Taxa de fiscalização de mineração (STN, 2007b - desde 1997)

Taxas do Departamento do Polícia Federal (STN, 2007b)

Taxa de fiscalização de prod. controlados pelo Min. do Exército (STN, 2007b)

Emolumentos e contrib. fisc. s/ prod. insumos químicos (STN, 2007b - desde 1999)

Taxa de classificação de produtos vegetais(STN, 2007b)

Taxa lic. contr. fisc. materiais e instalações nucleares/radioativos (STN, 2007b - desde 1999)

Cota-Parte da Contribuição Sindical

Contribuição DPVAT - Lei 8212/91 (até 2001)

45 Conforme mencionado no texto principal, não encontramos dados de alta freqüência para as contribuições ao "Sistema S".

46 Ignoramos nesse item vários impostos listados no Anexo 8 de IBGE (2004b) por terem arrecadações muito pequenas. 


\section{APÊNDICE 2 - AS ESTIMATIVAS TRIMESTRAIS PROPRIAMENTE DITAS}

\section{Tabela A.2 - Estimativas trimestrais da CTBB e de seus principais componentes (em R $\$$} bilhões correntes) ${ }^{*}$

\begin{tabular}{|c|c|c|c|c|c|c|}
\hline Período & $\begin{array}{l}\text { CTBB } \\
\text { nominal }\end{array}$ & $\begin{array}{l}\text { CTBB nom. cl } \\
\text { ajuste saz. }\end{array}$ & $\begin{array}{l}\text { CTBB como prop. do } \\
\text { PIB c/ ajuste saz. }\end{array}$ & $\begin{array}{c}\text { CPs } \\
\text { nominais }\end{array}$ & $\begin{array}{l}\text { IRPCs } \\
\text { nominais }\end{array}$ & $\begin{array}{l}\text { OlLPs } \\
\text { nominais }\end{array}$ \\
\hline $1995 \mathrm{~T} 1$ & 45,27 & 43,93 & 26,34 & 11,98 & 11,40 & 1,04 \\
\hline 1995 T2 & 47,89 & 49,28 & 28,92 & 12,43 & 10,47 & 2,17 \\
\hline 1995 T3 & 47,73 & 49,50 & 27,77 & 13,49 & 9,43 & 2,63 \\
\hline 1995 T4 & 52,10 & 50,51 & 26,89 & 16,12 & 9,43 & 2,82 \\
\hline $1996 \mathrm{~T} 1$ & 55,25 & 53,44 & 27,08 & 14,71 & 15,81 & 1,24 \\
\hline 1996 T2 & 53,17 & 54,81 & 27,13 & 14,85 & 11,01 & 2,49 \\
\hline 1996 T3 & 55,33 & 57,36 & 26,78 & 16,28 & 10,08 & 3,24 \\
\hline 1996 T4 & 62,38 & 60,63 & 26,67 & 20,15 & 11,70 & 3,45 \\
\hline 1997 T1 & 61,42 & 59,08 & 26,05 & 17,00 & 16,98 & 2,04 \\
\hline 1997 T2 & 60,01 & 62,08 & 26,85 & 16,82 & 14,53 & 1,75 \\
\hline 1997 T3 & 62,27 & 64,54 & 27,06 & 17,38 & 13,05 & 4,03 \\
\hline 1997 T4 & 68,51 & 66,76 & 27,75 & 20,63 & 15,76 & 3,70 \\
\hline 1998 T1 & 71,42 & 68,37 & 28,22 & 18,25 & 22,62 & 3,02 \\
\hline 1998 T2 & 65,61 & 67,97 & 27,49 & 18,48 & 15,13 & 3,02 \\
\hline 1998 T3 & 66,61 & 69,07 & 27,91 & 18,85 & 16,42 & 3,09 \\
\hline 1998 T4 & 70,73 & 69,18 & 28,70 & 22,22 & 16,20 & 3,79 \\
\hline 1999 T1 & 79,13 & 75,36 & 29,38 & 21,17 & 22,93 & 3,06 \\
\hline 1999 T2 & 71,66 & 74,31 & 28,19 & 19,88 & 15,47 & 2,77 \\
\hline 1999 T3 & 75,96 & 78,84 & 29,92 & 20,47 & 17,66 & 3,11 \\
\hline 1999 T4 & 83,31 & 81,70 & 29,22 & 23,86 & 19,47 & 3,06 \\
\hline 2000 T1 & 90,12 & 85,67 & 30,33 & 22,79 & 27,46 & 3,04 \\
\hline 2000 T2 & 84,45 & 87,30 & 30,31 & 21,80 & 20,72 & 3,11 \\
\hline 2000 T3 & 87,01 & 90,54 & 30,16 & 23,13 & 18,74 & 2,93 \\
\hline 2000 T4 & 96,55 & 94,87 & 30,88 & 27,12 & 22,18 & 3,15 \\
\hline 2001 T1 & 102,26 & 97,10 & 30,24 & 25,01 & 28,65 & 3,81 \\
\hline 2001 T2 & 102,55 & 105,68 & 32,97 & 25,88 & 25,56 & 3,94 \\
\hline 2001 T3 & 100,41 & 104,82 & 32,30 & 25,76 & 24,17 & 3,52 \\
\hline 2001 T4 & 109,72 & 107,67 & 32,13 & 31,14 & 27,68 & 3,80 \\
\hline 2002 T1 & 119,00 & 113,33 & 32,27 & 27,70 & 39,16 & 4,34 \\
\hline 2002 T2 & 112,76 & 115,62 & 31,56 & 28,04 & 30,21 & 4,61 \\
\hline 2002 T3 & 116,79 & 122,42 & 32,83 & 30,57 & 30,24 & 4,41 \\
\hline 2002 T4 & 129,53 & 126,70 & 32,88 & 36,32 & 32,83 & 4,69 \\
\hline 2003 T1 & 136,34 & 130,30 & 32,20 & 32,52 & 42,11 & 5,11 \\
\hline 2003 T2 & 132,39 & 135,33 & 32,48 & 32,32 & 37,38 & 5,52 \\
\hline 2003 T3 & 129,29 & 135,89 & 31,56 & 34,05 & 33,40 & 5,06 \\
\hline 2003 T4 & 144,25 & 140,46 & 31,51 & 42,44 & 37,10 & 5,57 \\
\hline 2004 T1 & 159,57 & 153,25 & 33,11 & 38,12 & 48,84 & 6,71 \\
\hline 2004 T2 & 150,38 & 153,32 & 31,72 & 38,39 & 38,65 & 5,82 \\
\hline 2004 T3 & 154,50 & 162,79 & 33,20 & 40,99 & 38,46 & 5,92 \\
\hline 2004 T4 & 172,81 & 167,46 & 33,34 & 50,18 & 42,59 & 6,50 \\
\hline 2005 T1 & 179,39 & 172,96 & 33,67 & 42,76 & 55,76 & 7,87 \\
\hline 2005 T2 & 176,78 & 180,16 & 33,81 & 43,68 & 51,94 & 6,20 \\
\hline 2005 T3 & 172,87 & 182,31 & 33,63 & 45,19 & 44,11 & 6,77 \\
\hline 2005 T4 & 197,32 & 190,38 & 34,28 & 54,48 & 53,91 & 7,15 \\
\hline $2006 \mathrm{~T} 1$ & 198,29 & 191,94 & 34,13 & 49,29 & 60,93 & 9,28 \\
\hline 2006 T2 & 194,40 & 197,96 & 34,82 & 49,98 & 57,42 & 7,61 \\
\hline 2006 T3 & 194,36 & 205,19 & 34,61 & 52,69 & 50,61 & 7,94 \\
\hline 2006 T4 & 219,20 & 210,87 & 34,79 & 63,78 & 55,06 & 8,49 \\
\hline 2007 T1 & 221,13 & 214,44 & 34,57 & 55,18 & 71,82 & 8,59 \\
\hline 2007 T2 & 218,83 & 222,90 & 35,17 & 56,48 & 65,24 & 9,16 \\
\hline 2007 T3 & 220,58 & 232,92 & 36,12 & 59,49 & 58,54 & 8,55 \\
\hline 2007 T4 & 252,27 & 242,27 & 36,87 & 72,10 & 69,25 & 8,60 \\
\hline
\end{tabular}

Nota: *Os valores apresentados para 1995 partem do pressuposto que o dado do SCN 2003 (IBGE, 2004a) para as contribuições previdenciárias desse ano estão equivocados. 